\title{
Pulmonary embolism in patients with COVID-19 and value of D-dimer assessment: a meta-analysis
}

\author{
Robert M. Kwee ${ }^{1}$ (D) Hugo J. A. Adams ${ }^{2} \cdot$ Thomas C. Kwee $^{3}$ \\ Received: 12 February 2021 / Revised: 24 March 2021 / Accepted: 19 April 2021 / Published online: 9 May 2021 \\ (C) European Society of Radiology 2021
}

\begin{abstract}
Purpose To investigate, in a meta-analysis, the frequency of pulmonary embolism (PE) in patients with COVID-19 and whether D-dimer assessment may be useful to select patients for computed tomography pulmonary angiography (CTPA).

Methods A systematic literature search was performed for original studies which reported the frequency of PE on CTPA in patients with COVID-19. The frequency of PE, the location of PE, and the standardized mean difference (SMD) of D-dimer levels between patients with and without PE were pooled by random effects models.

Results Seventy-one studies were included. Pooled frequencies of PE in patients with COVID-19 at the emergency department (ED), general wards, and intensive care unit (ICU) were $17.9 \%$ (95\% CI: $12.0-23.8 \%$ ), 23.9\% (95\% CI: $15.2-32.7 \%$ ), and $48.6 \%$ (95\% CI: 41.0-56.1\%), respectively. PE was more commonly located in peripheral than in main pulmonary arteries (pooled frequency of $65.3 \%$ [95\% CI: $60.0-70.1 \%$ ] vs. $32.9 \%$ [95\% CI: $26.7-39.0 \%]$; OR $=3.540$ [95\% CI: 2.308-5.431\%]). Patients with PE had significantly higher D-dimer levels (pooled SMD of 1.096 [95\% CI, 0.844-1.349]). D-dimer cutoff levels which have been used to identify patients with PE varied between 1000 and $4800 \mu \mathrm{g} / \mathrm{L}$.

Conclusion The frequency of PE in patients with COVID-19 is highest in the ICU, followed by general wards and the ED. PE in COVID-19 is more commonly located in peripheral than in central pulmonary arteries, which suggests local thrombosis to play a major role. D-dimer assessment may help to select patients with COVID-19 for CTPA, using D-dimer cutoff levels of at least $1000 \mu \mathrm{g} / \mathrm{L}$.

Key Points

- The frequency of PE in patients with COVID-19 is highest in the ICU, followed by general wards and the ED.

- PE in COVID-19 is more commonly located in peripheral than in central pulmonary arteries.

- D-dimer levels are significantly higher in patients with COVID-19 who have PE.
\end{abstract}

Keywords Coronavirus $\cdot$ Pulmonary embolism $\cdot$ Coagulation $\cdot$ Tomography $\cdot$ Diagnosis

\begin{tabular}{|c|c|c|c|}
\hline \multicolumn{2}{|c|}{ Abbreviations } & \multirow[t]{2}{*}{ CTPA } & \multirow{2}{*}{$\begin{array}{l}\text { Computed tomography pulmonary } \\
\text { angiography }\end{array}$} \\
\hline CI & Confidence interval & & \\
\hline \multirow[t]{6}{*}{ COVID-19 } & Coronavirus disease 2019 & ED & Emergency department \\
\hline & & ICU & Intensive care unit \\
\hline & & OR & Odds ratio \\
\hline & & PE & Pulmonary embolism \\
\hline & & SD & Standard deviation \\
\hline & & SMD & Standardized mean difference \\
\hline
\end{tabular}

rmkwee@gmail.com

1 Department of Radiology, Zuyderland Medical Center, Heerlen/Sittard/Geleen, The Netherlands

\section{Introduction}

2 Utrecht, The Netherlands

3 Department of Radiology, Nuclear Medicine and Molecular Imaging, University Medical Center Groningen, University of Groningen, Groningen, The Netherlands

The ongoing coronavirus disease 2019 (COVID-19) pandemic has caused dramatic effects on society. On March 21, 2021, more than 122 million people have been infected and more 
than 2.7 million people have died of the disease worldwide [1]. Although approximately $80 \%$ of patients with COVID-19 have a favorable clinical course without hospitalization [2], approximately $20 \%$ of patients experiences severe respiratory disease [2]. A high incidence of thromboembolic events, including pulmonary embolism (PE), has been observed in COVID-19, which suggests that COVID-19 may induce intravascular coagulopathy [3-6]. PE may be a direct cause of death in patients with COVID-19, despite the use of antithrombotic prophylaxis [4, 6, 7]. Patients with COVID-19 who experience PE should be managed in a timely manner with therapeutic doses of anticoagulant therapy [8]. Computed tomography pulmonary angiography (CTPA) is the preferred imaging modality to detect PE [9]. To date, the frequency of $\mathrm{PE}$ in patients with COVID-19 is not completely clear. As such, it is still unclear which patients should undergo CTPA to detect PE. Unfortunately, clinical pretest probability scores, such as the Wells criteria [10], are unreliable to predict the occurrence of PE in patients with COVID-19 [11-14]. It has been suggested that assessment of D-dimer levels may help to improve risk stratification for $\mathrm{PE}[5,15]$, but the exact value is also not completely clear. In order to overcome these gaps in knowledge, it was our purpose to investigate, in a meta-analysis, the frequency of PE in patients with COVID-19, and whether D-dimer assessment may be useful to select patients with COVID-19 for CTPA.

\section{Materials and methods}

This study followed the Preferred Reporting Items for Systematic Reviews and Meta-Analyses guideline [16]. Institutional review board approval was not applicable.

\section{Study retrieval and selection}

MEDLINE and Embase were searched using the following search string: (Corona OR Coronavirus OR Covid-19 OR SARS-Cov-2 OR 2019nCoV OR Wuhan-virus) AND (Computed tomography OR Computerized tomography OR Computed tomographic OR CT OR CAT OR CTPA) AND (pulmonary embolism OR PE OR pulmonary thromboembolism OR PTE OR pulmonary thrombosis). Furthermore, the journal Radiology: Cardiothoracic Imaging was manually searched for relevant studies (articles published by this journal were not listed yet in MEDLINE and Embase). The search was updated until March 14, 2021. Bibliographies of studies which were included in our meta-analysis were screened for potentially suitable references.

Original studies which reported the frequency of PE on CTPA scans performed in at least 10 patients with COVID19 (regardless of PE frequency) were eligible for inclusion.
Review articles, abstracts, and studies involving fewer than 10 patients were excluded. Using these selection criteria, titles and abstracts of studies were reviewed. The full text versions of potentially relevant studies were then reviewed to determine whether studies could be included in our meta-analysis. Bibliographies of included studies were screened for other potential relevant studies. Two reviewers (R.M.K. and H.J.A.A.) independently performed the study selection. Any discrepancies were solved by consensus with a third reviewer (T.C.K.).

\section{Study data extraction and study quality assessment}

Main study characteristics (country of origin, patient inclusion period, number of patients, age and gender of patients, indication for CTPA, use of antithrombotic prophylaxis before CTPA, and CT interpreter(s)) were extracted for each included study. The proportions of patients with and without PE were extracted. If reported, data were extracted for patients with COVID-19 who presented at the emergency department (ED), for patients with COVID-19 who had been admitted to general wards, and for patients with COVID-19 who had been admitted to the intensive care unit (ICU). Furthermore, we extracted the association between severity of COVID-19 at chest $\mathrm{CT}$ and PE, if reported by the included studies. We also extracted the locations of PEs (i.e., main, lobar, segmental, and subsegmental pulmonary arteries) on a per-patient basis if reported by the included studies. In addition, for studies which reported D-dimer levels for patients with and without PE, we extracted the mean values and standard deviations (SDs). Corresponding authors of studies which did not report mean values and SDs were contacted and requested to provide these values. We also extracted sensitivity and specificity values for different D-dimer cutoff levels, if reported by the included studies.

Study quality aspects were assessed by two independent reviewers (R.M.K. and H.J.A.A.) using items from the Newcastle-Ottawa quality assessment scale [17] which were adapted to our meta-analysis (Table 1). Any discrepancies were solved by consensus with a third reviewer (T.C.K.).

\section{Statistical analyses}

The frequencies of PE in patients with COVID-19 were determined for each included study and pooled with a random effects model. For studies which reported the frequency of PE in both patients with COVID-19 and those without COVID-19, differences were assessed by a chi-square test [18]. The frequencies of central (main and lobar) and peripheral (segmental and subsegmental) PEs were also pooled with a random effects model and the odds ratio (OR) of peripheral vs. central PEs was calculated. Differences in D-dimer levels 
Table 1 Criteria to evaluate the quality of included studies

\begin{tabular}{ll}
\hline Quality items & Signaling questions \\
\hline $\begin{array}{l}\text { Type of cohort study } \\
\text { Method of patient } \\
\text { selection }\end{array}$ & Does the study have a prospective or retrospective design? \\
$\begin{array}{l}\text { Watient spectrum } \\
\text { Blinded assessment of } \\
\text { outcome }\end{array}$ & Were selection criteria for CTPA reported? \\
\hline
\end{tabular}

between patients with COVID-19 vs. those without PE were assessed by calculating the standardized mean difference (SMD). The pooled SMD was estimated by a random effects model. Heterogeneity was tested by the $I^{2}$ statistic [19]. If significant heterogeneity was present (defined as $I^{2}>40 \%$ [20]), subgroup analyses were performed to explore potential sources of heterogeneity. Predefined covariates were "indication for CTPA" (study reported that was CTPA only performed if PE was clinically suspected vs. study reported that CTPA was performed for triaging or on a routine basis, but not necessarily because of clinically suspected PE), "use of antithrombotic prophylaxis before CTPA" (100\% vs. < $100 \%$ of included patients who used antithrombotic prophylaxis before CTPA), and "way of CTPA interpretation" (blinding vs. no blinding of CTPA interpreters to clinical information). Statistical analyses were performed using the Open MetaAnalyst software package [21], and MedCalc Statistical Software (MedCalc Software) [22]. $p$ values $<0.05$ were considered statistically significant for all analyses.

\section{Results}

\section{Study retrieval and selection}

The study selection process is summarized in Fig. 1. After screening titles and abstracts, 130 potentially relevant studies remained and were retrieved in full text. After reviewing the full text, 52 studies were excluded because there was no reporting of $\mathrm{PE}$ frequency data with respect to the number of CTPA scans performed in patients with COVID-19, 6 studies were excluded because these studies did not allow separate data extraction of patients with and without COVID-19, 2 studies were excluded because they comprised fewer than 10 patients with COVID-19, and 1 study was excluded because in this study PE was also determined based on clinical grounds rather than by CTPA only. Two additional references were found by screening bibliographies of remaining studies. Finally, 71 studies [11, 23-92], which comprised a total of 8086 patients with COVID-19 who underwent CTPA to evaluate for PE (median of 55 patients per study, range 10-1240), were included in our meta-analysis. Main study characteristics are displayed in Table 2.

\section{Study quality}

Details with regard to individual study quality are displayed in Supplemental Table 1. Eight studies $(11.3 \%)$ had a prospective design, whereas 58 included studies $(81.7 \%)$ had a retrospective design, whereas in 5 studies $(7.0 \%)$ it was not reported whether the study design was prospective or retrospective. All but one of the included studies consecutively or randomly selected patients, or obviously comprised a representative series of patients. In 55 studies $(77.5 \%)$, patient selection criteria for CTPA were reported, in 15 studies $(21.1 \%)$, patient selection criteria for CTPA were not reported, whereas in 1 study (1.4\%), patient selection criteria for CTPA were only reported for a subset of patients. CTPA interpreters were blinded to clinical information in 15 studies $(21.1 \%)$, and unblinded in 2 studies $(2.8 \%)$ whereas this was not clear (not reported) in the remaining 54 studies $(76.1 \%)$.

\section{Frequency of PE in patients with COVID-19}

Pooled frequency of PE in all included patients with COVID19 was $32.1 \%$ (95\% confidence interval [CI]: 28.5-35.9\%). Pooled frequency of PE was lowest in patients who presented at the ED (17.9\% [95\% CI: 12.0-23.8\%]) (Fig. 2), followed by patients who had been admitted to general wards $(23.9 \%$ [95\% CI: 15.2-32.7\%] (Fig. 3). In patients with COVID-19 who had been admitted to the ICU, pooled frequency of PE was highest (48.6\% [95\% CI: 41.0-56.1\%]) (Fig. 4).

Significant heterogeneity was present across the included studies $\left(I^{2} \geq 80 \%\right)$. No potential sources of heterogeneity were identified $\left(I^{2}>85 \%\right)$ for subgroups according to "indication for CTPA," "use of antithrombotic prophylaxis before CTPA," and "way of CTPA interpretation." In two studies which routinely performed CTPA at the ED (regardless of clinical suspicion of PE), PE frequencies in COVID-19 patients were $2.1 \%(1 / 48)$ and $5.7 \%$ (4/70), respectively $[29,50]$. In two other studies which routinely performed CTPA at the ICU (regardless of clinical suspicion of PE), PE frequencies in COVID-19 patients were $47.2 \%(34 / 72)$ and 60.0\% (12/20), 


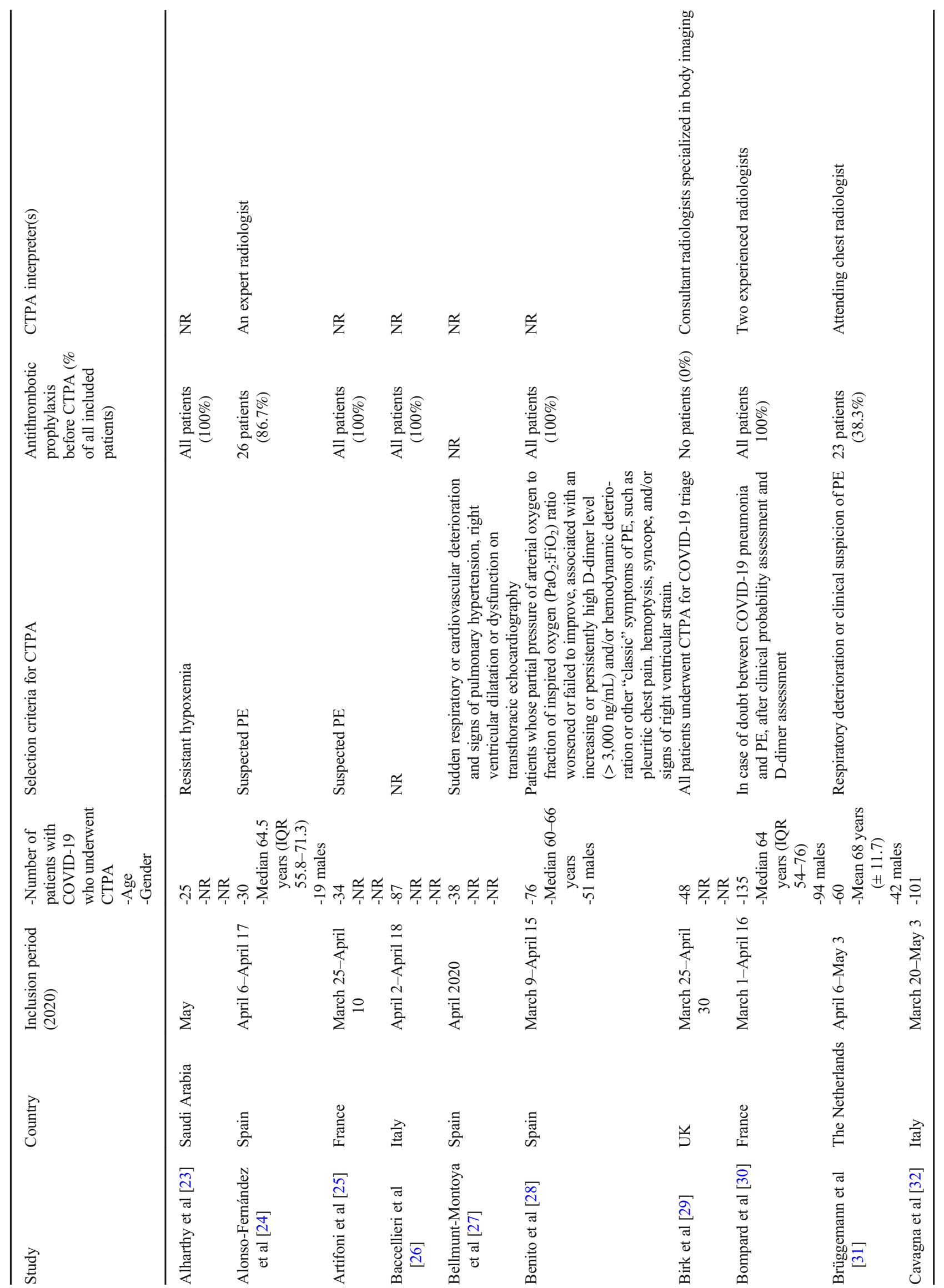


离

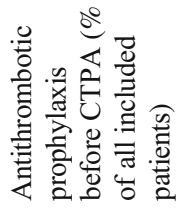

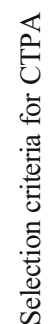

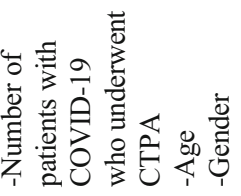

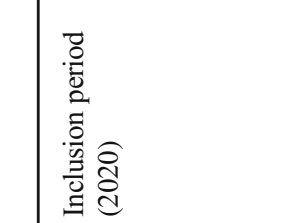

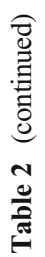

题起

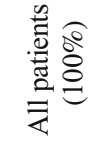

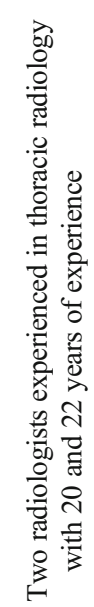

号孚

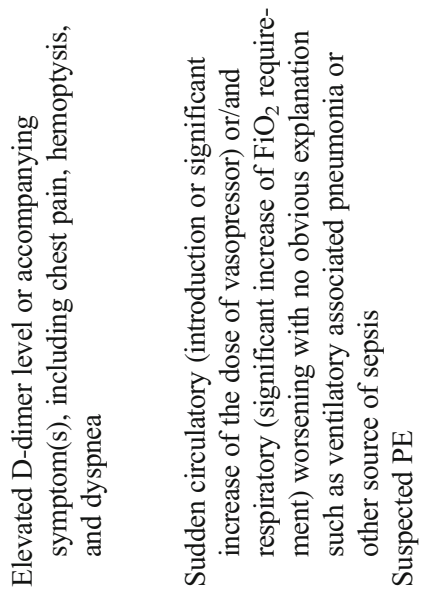

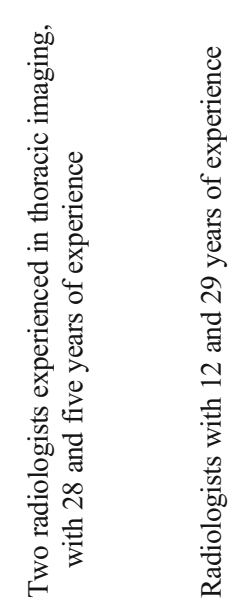

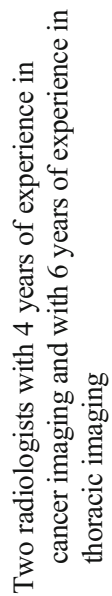

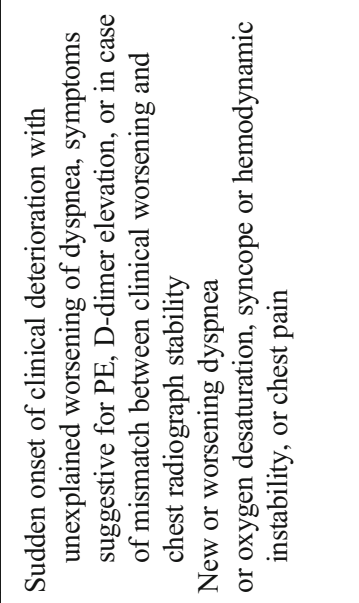

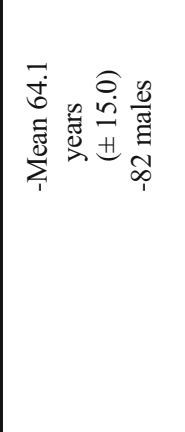

定

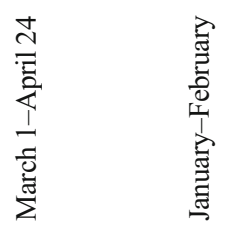

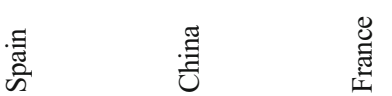

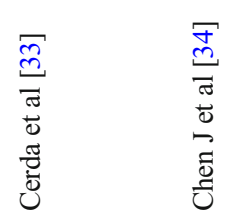

尊

喜

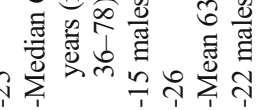

密

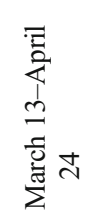

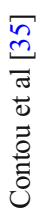

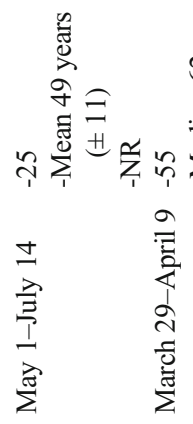

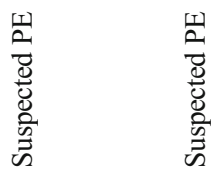

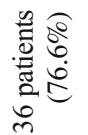

艺
告

( 


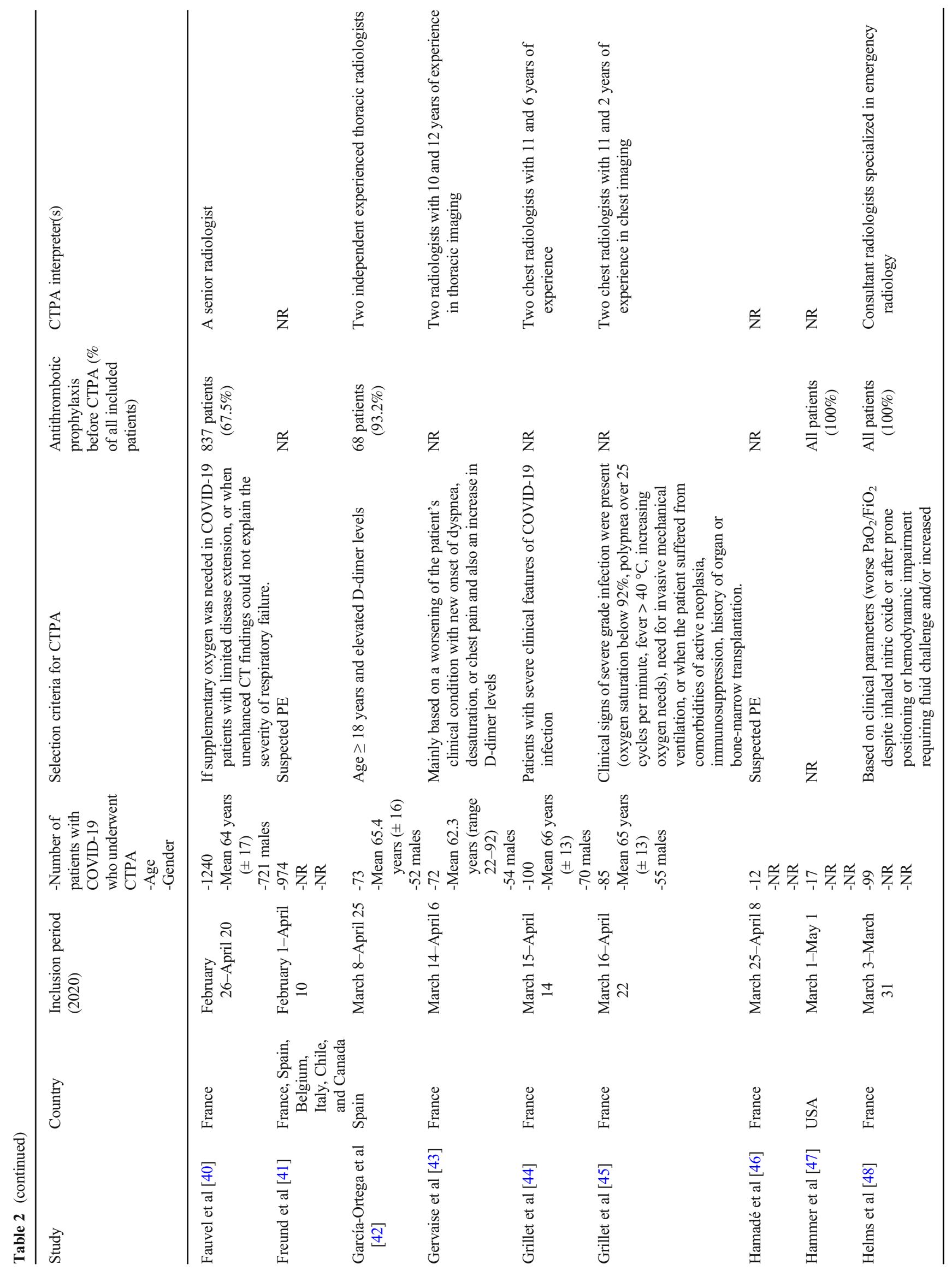




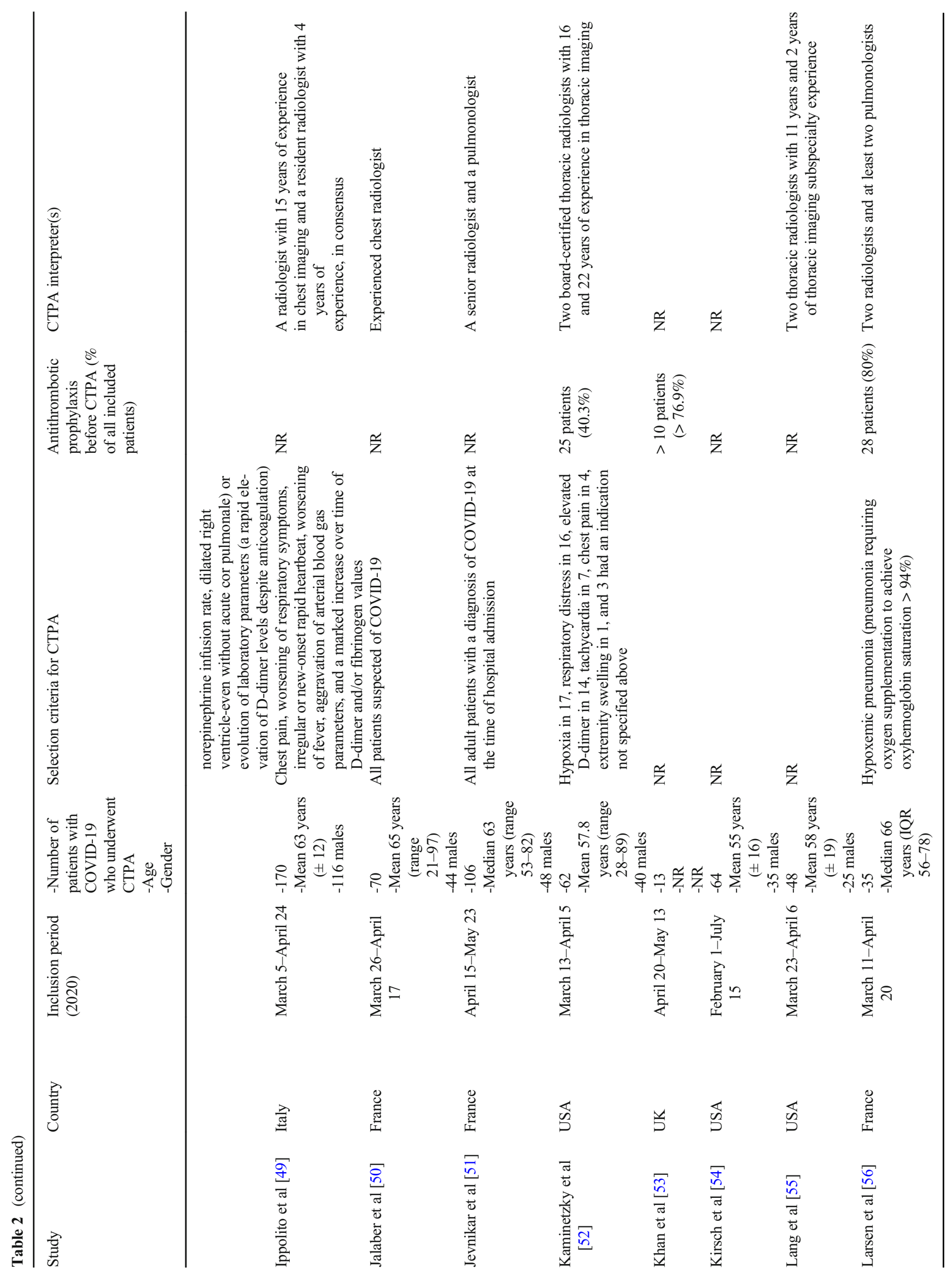




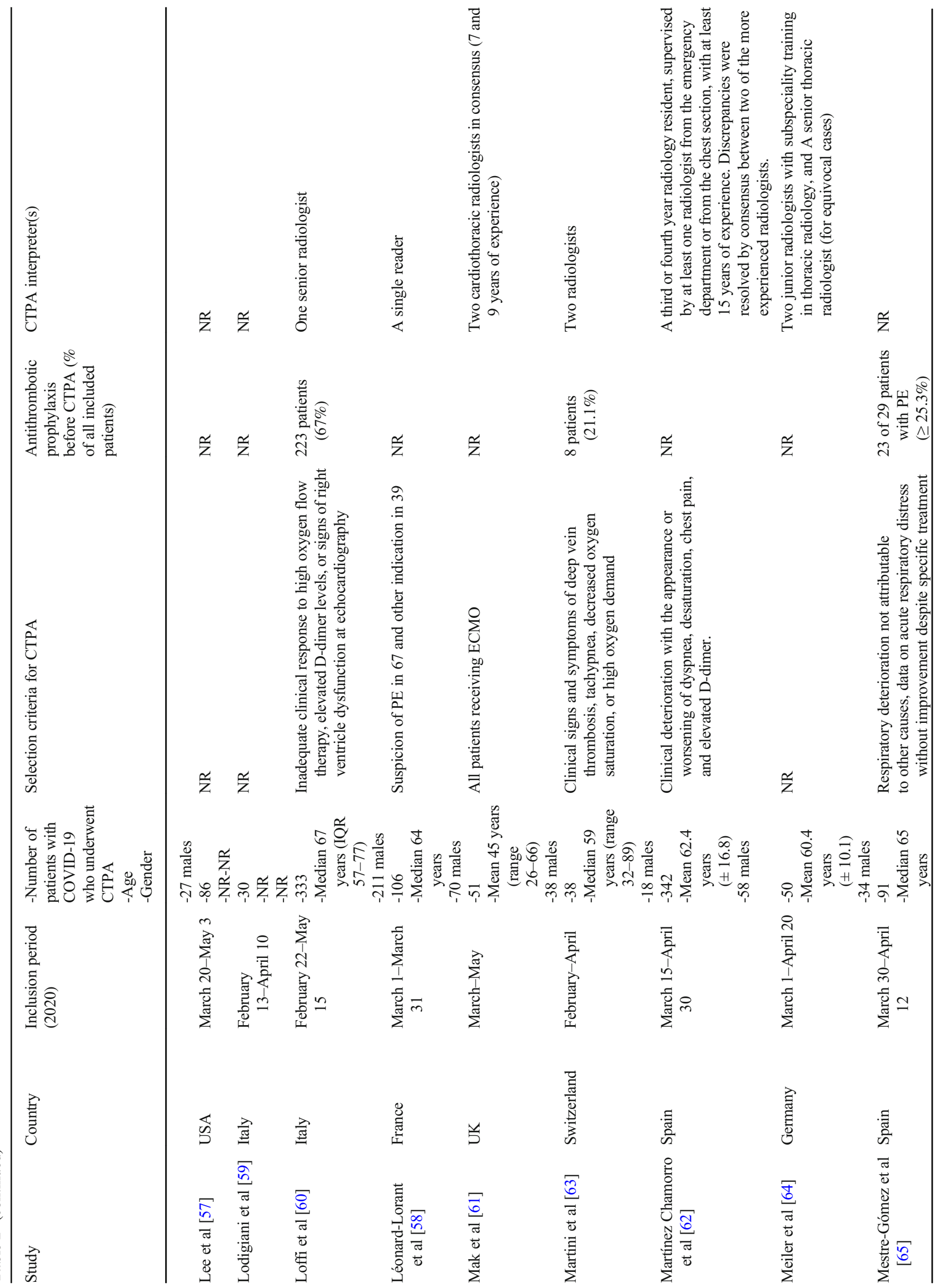



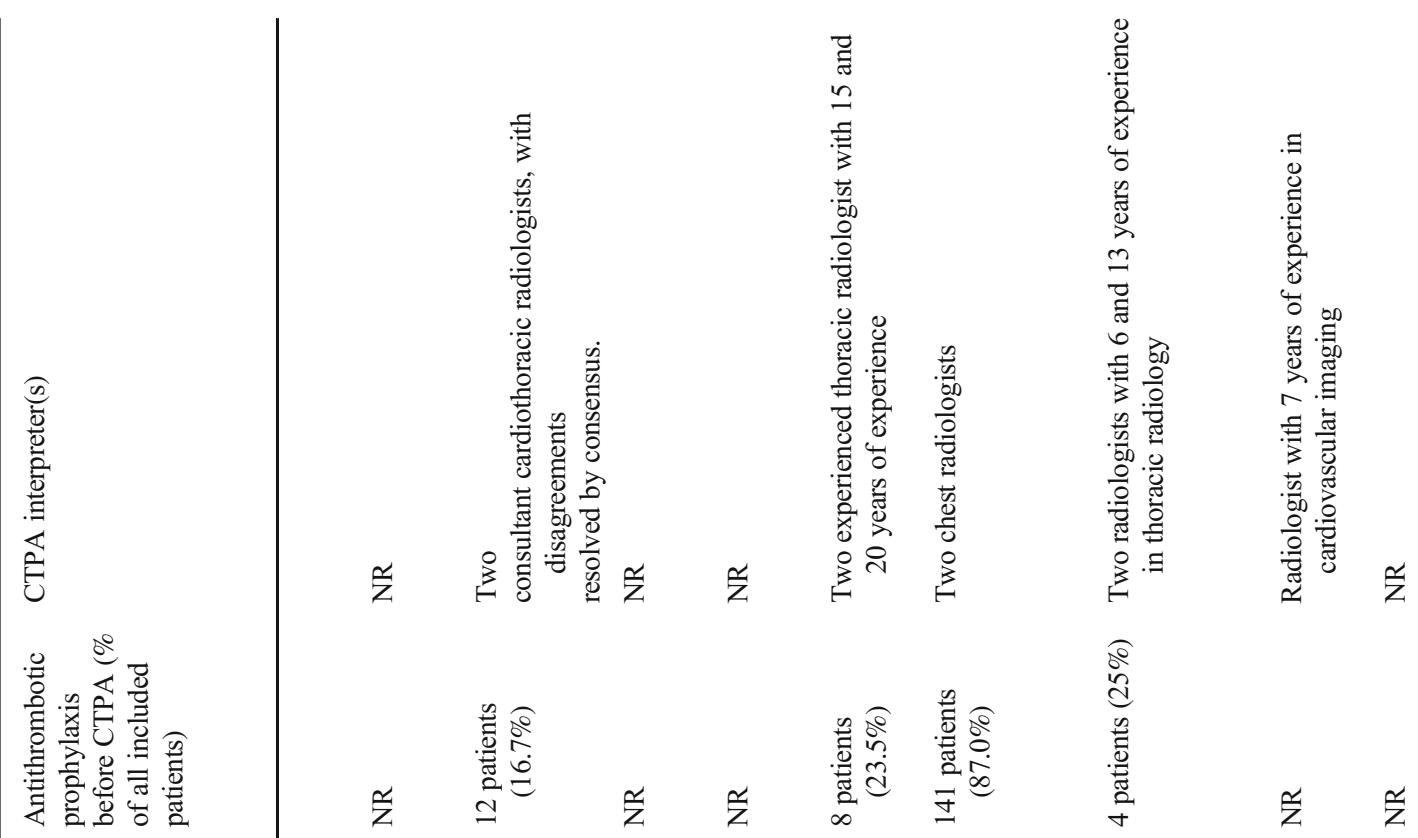

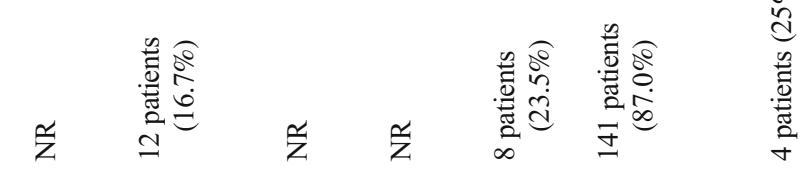
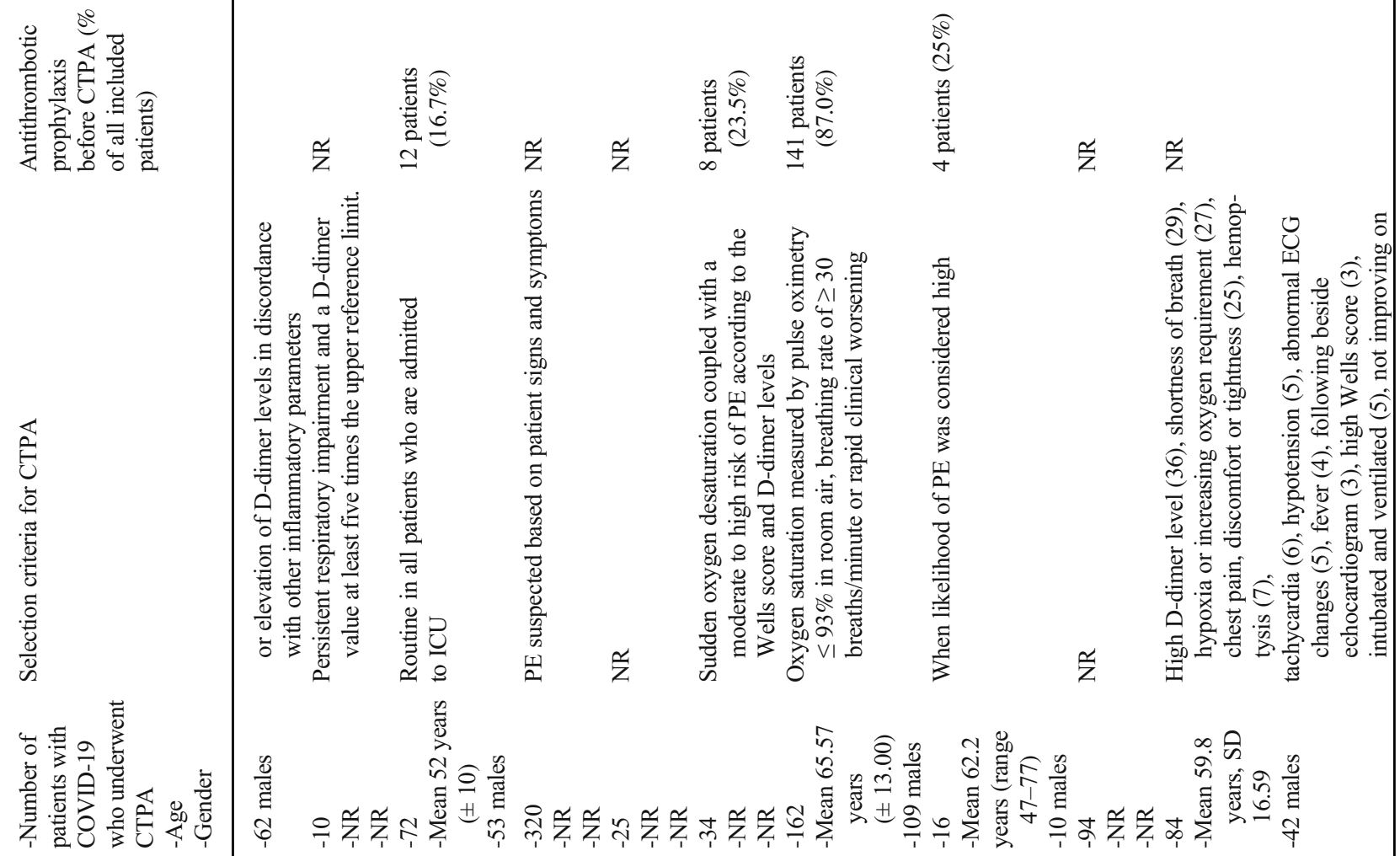

离

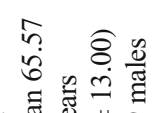

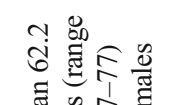

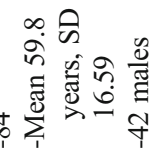

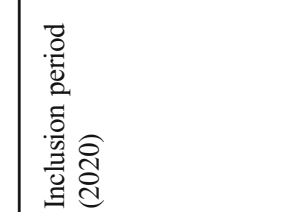

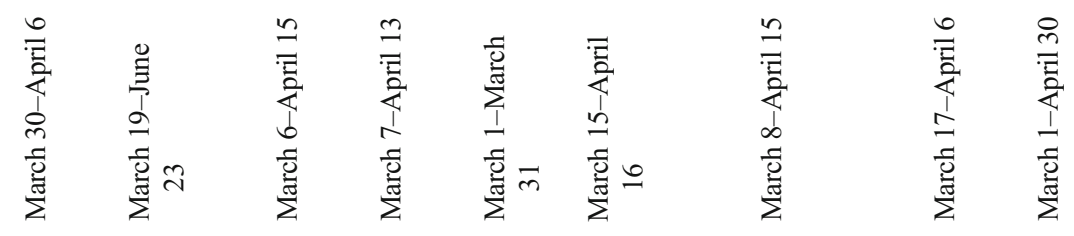

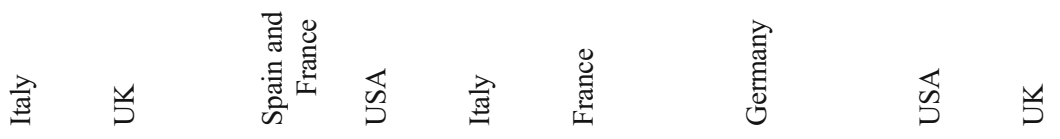

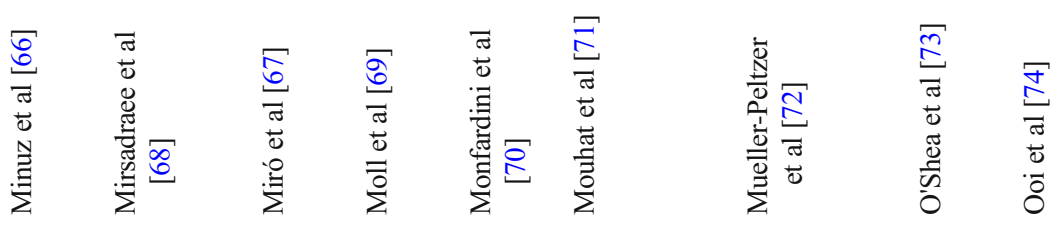




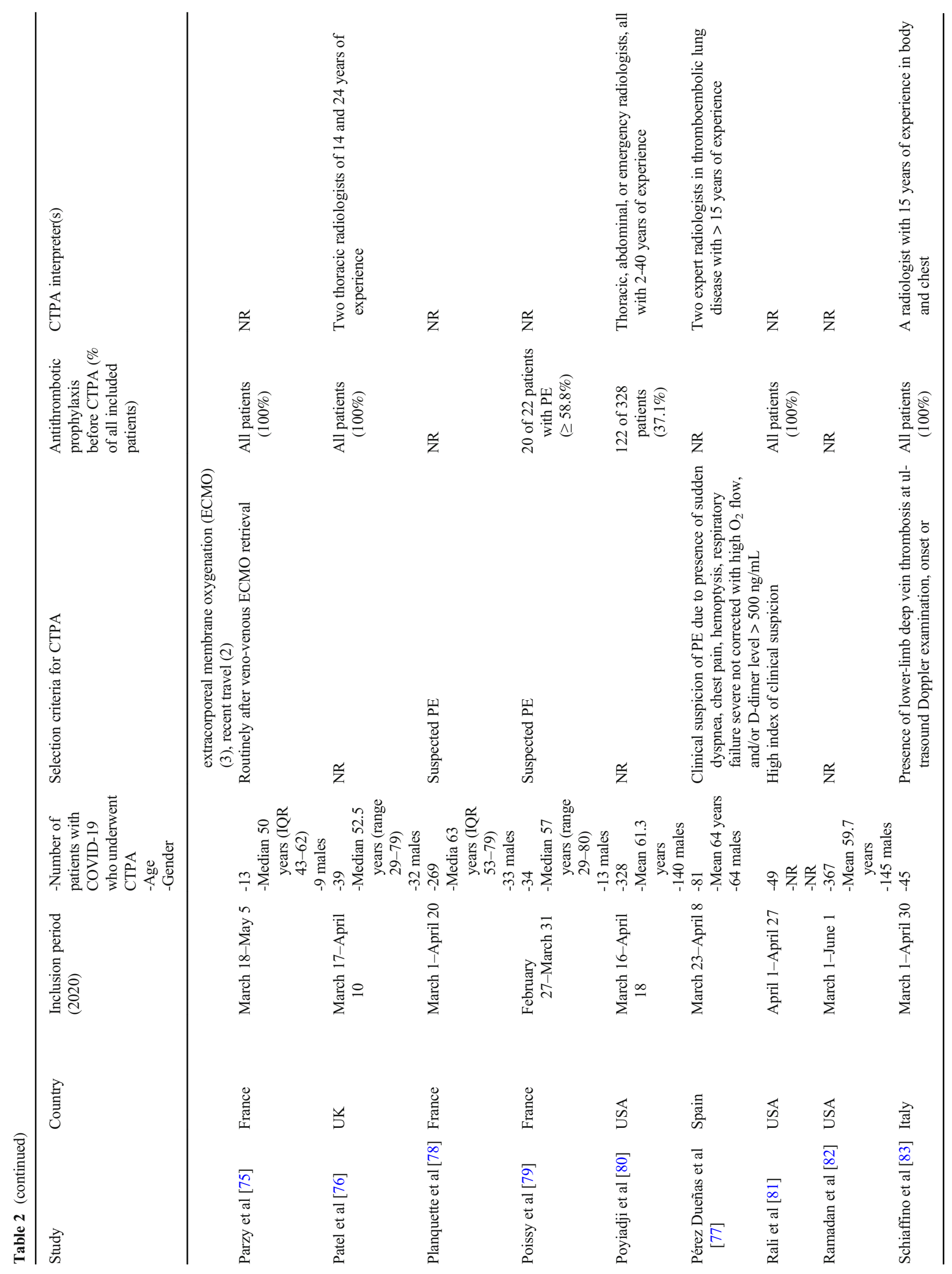



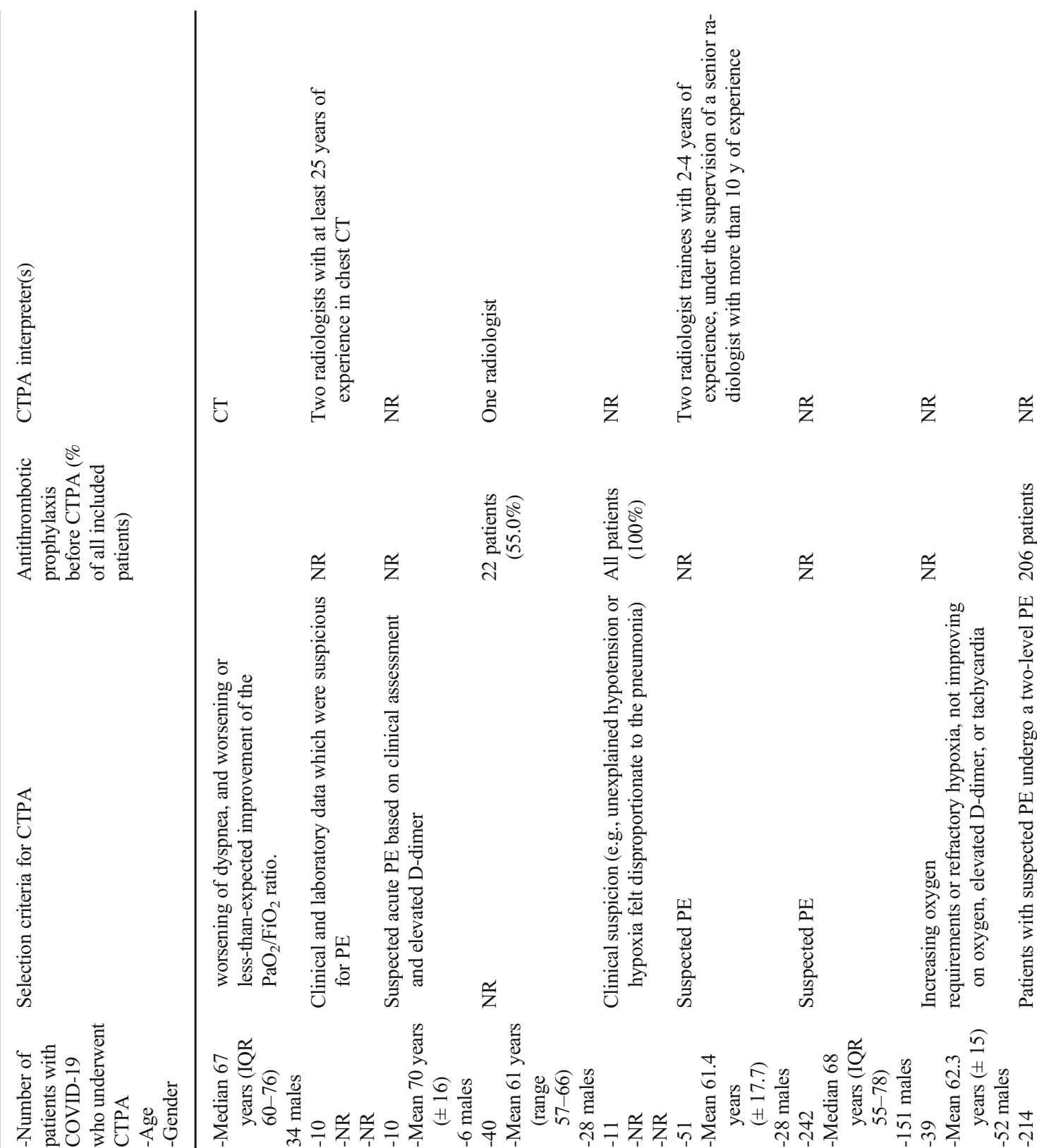

艺

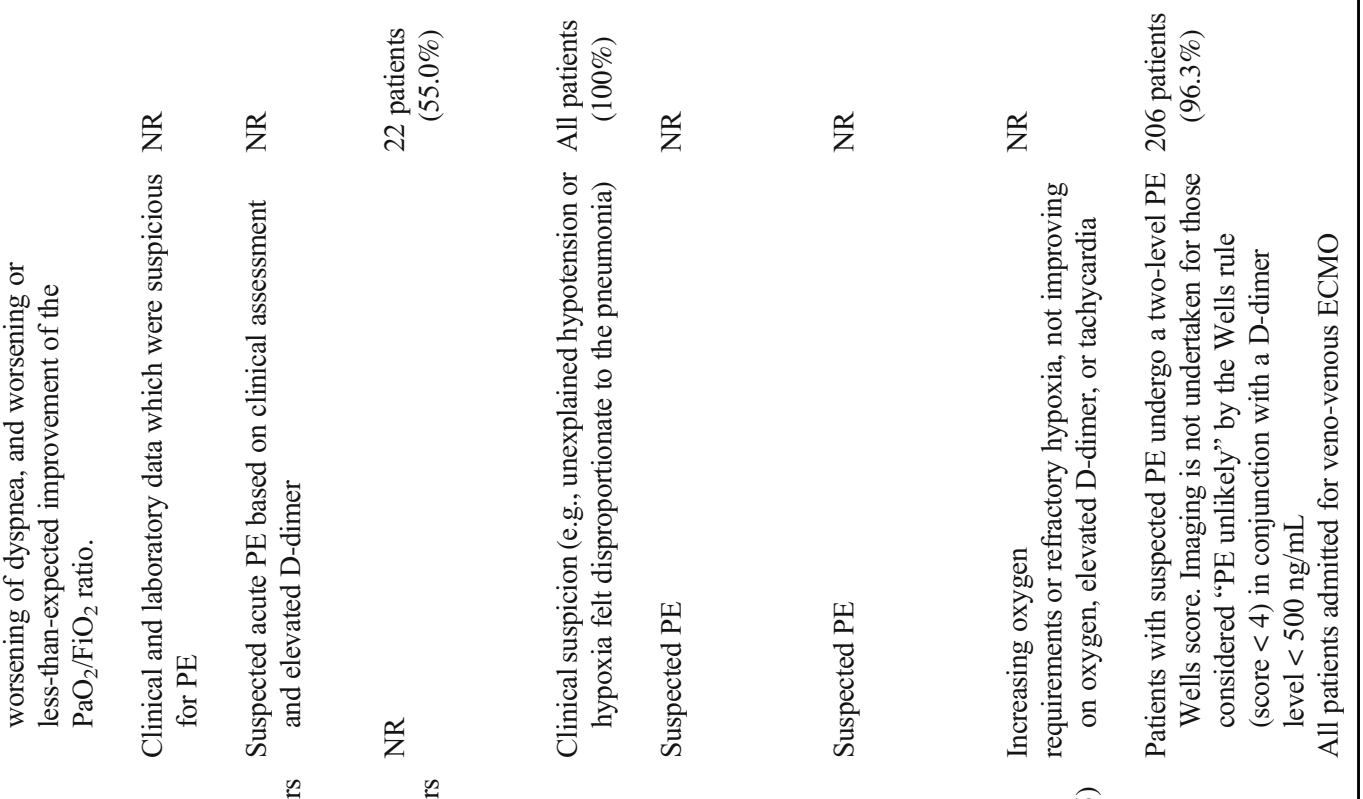

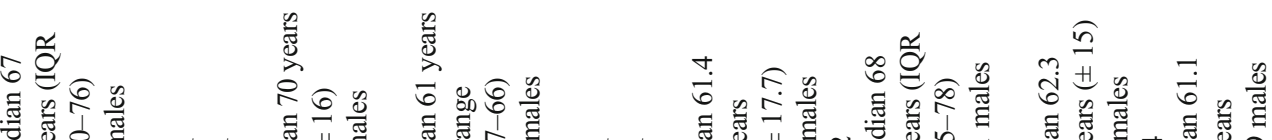

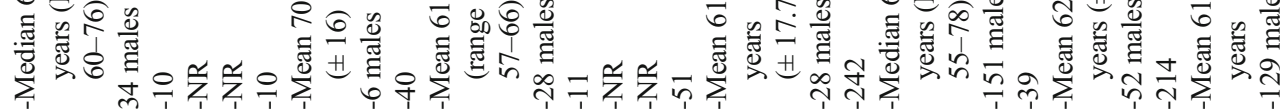

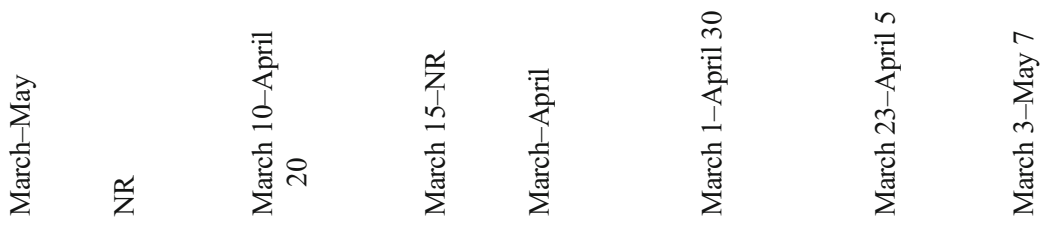

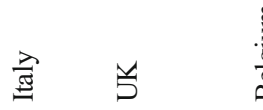

恶
0
0
0
0
0
$\overline{0}$
0
0
0
0
0
0

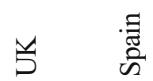

苋

光 光

䒓

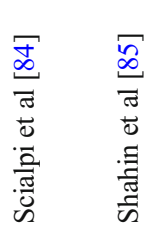

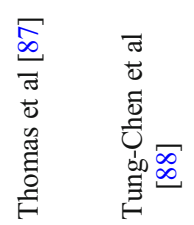

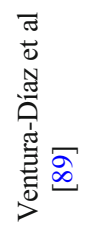

$\overline{2}$
$\frac{5}{\pi}$
0
$\frac{0}{0}$
$\frac{\pi}{3}$

$\Xi$
$\Xi$
$\frac{\pi}{0}$
$\frac{0}{3}$
3

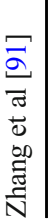


respectively studies $[68,92]$. Six studies reported a significant association between severity of COVID-19 at chest CT and PE, whereas 13 studies did not find a significant association (Supplemental Table 2).

\section{PE location}

PE was more commonly located in peripheral than in main pulmonary arteries (pooled frequency of $65.3 \%$ [95\% CI: 60.0-70.1\%] vs. $32.9 \%$ [95\% CI: $26.7-39.0 \%] ; \mathrm{OR}=3.540$ [95\% CI: $2.308-5.431 \%]$ ).

\section{PE in patients with COVID-19 and association with D-} dimer levels

Patients with COVID-19 and PE had significantly higher Ddimer levels than patients with COVID-19 and no PE (pooled SMD of 1.096 [95\% CI, 0.844-1.349]; $\mathrm{I}^{2}=89 \%$ ) (Fig. 5). Sensitivity and specificity values for different D-dimer cutoff levels are displayed in Table 3. D-dimer cutoff levels which have been used to identify patients with PE varied between 1000 and $4800 \mu \mathrm{g} / \mathrm{L}$. All studies listed in Table 3 used the conventional D-dimer score. Only one study also used ageadjusted D-dimer cutoffs [93], yielding a sensitivity of $94 \%$ and a specificity of $35 \%$ [33].

\section{Discussion}

This meta-analysis showed that the frequency of PE in COVID-19 was highest in patients who were in the ICU (pooled frequency of $48.6 \%$ ), followed by patients who were in general wards (pooled frequency of 23.9\%), and by patients who presented at the ED (pooled frequency of 17.9\%). PE was more commonly located in peripheral than in main pulmonary arteries (pooled frequency of $65.3 \%$ vs. $32.9 \%$ ). Patients with PE had significantly higher D-dimer levels than patients without PE.

Fifty-eight of the 71 included studies $(81.7 \%)$ had a retrospective design. However, there was no evidence of selection bias, as all but one of the studies included a consecutive, randomly selected, or obviously representative series of patients. Selection criteria for CTPA were reported in the majority of included studies (77.5\%), which benefits the generalizability of study results. In only $21.1 \%$ of included studies, it was reported that CTPA interpreters were blinded to clinical information. Non-blinding could have biased the results to either overcalling or undercalling PE frequency on CTPA.

The findings of our meta-analysis suggest that the frequency of PE in patients with COVID-19 increases with increasing disease severity (ICU > general wards and ED). This is supported by six studies which reported a significant association between severity of lung parenchymal abnormalities at CT 
Fig. 1 Flow diagram of the study selection process

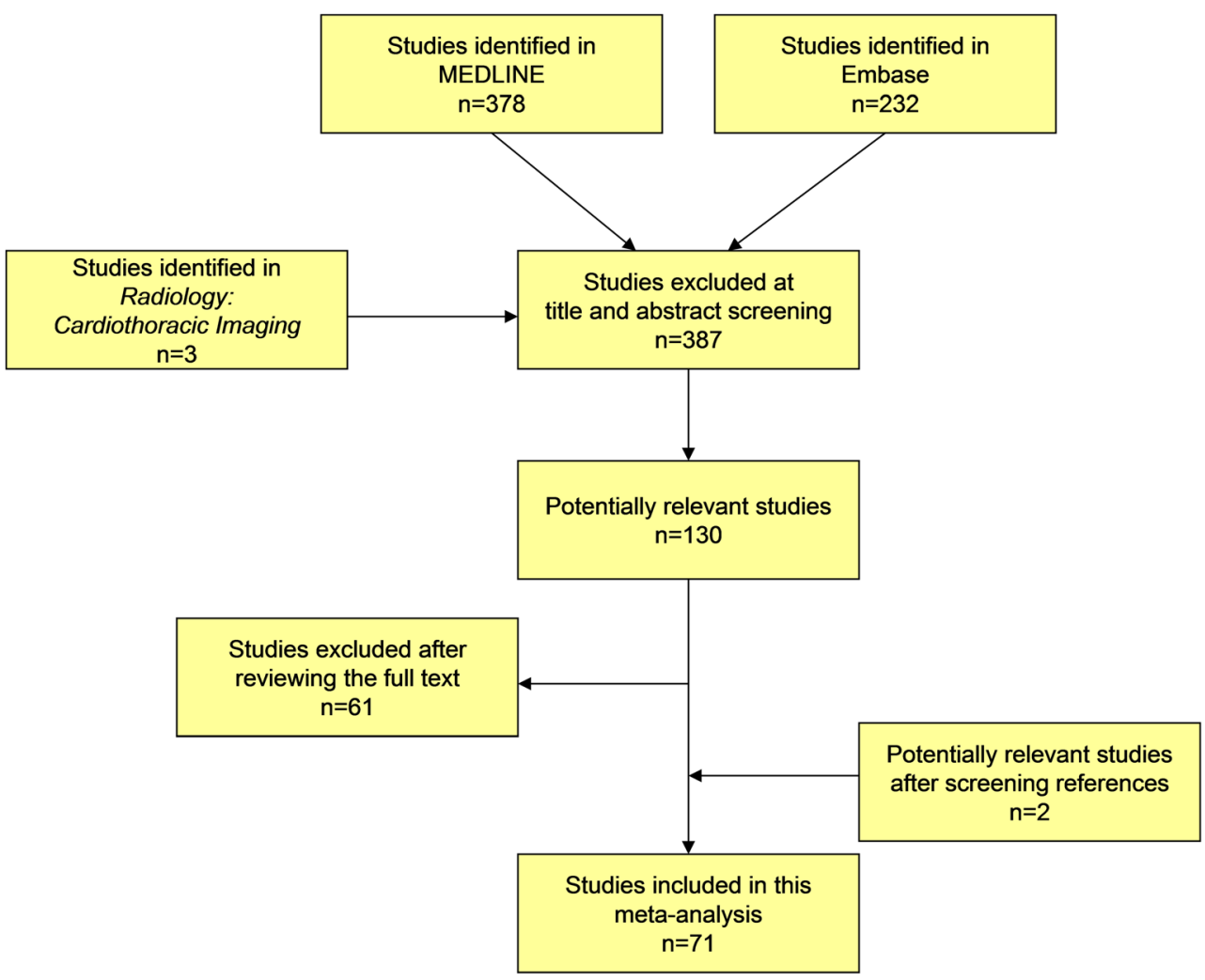

Studies

Benito et al. [28] Birk et al. [29]

Brüggemann et al. [31]

Fang et al. [39]

Freund et al. [41]

Gervaise et al. [43]

Grillet et al. [45]

Jalaber et al. [50]

Miró et al. [67]

Ramadan et al. [82]

Tung-Chen et al. [88]

Overall $(1 \wedge 2=88 \%, P<0.001) \quad 0.179(0.120,0.238)$
Estimate (95등.I.)
$0.400(0.096,0.704)$

$0.021(0.000,0.061)$

$0.261(0.081,0.440)$

$0.500(0.300,0.700)$

$0.152(0.129,0.174)$

$0.181(0.092,0.269)$

$0.222(0.000,0.494)$

$0.057(0.003,0.112)$

$0.184(0.142,0.227)$

$0.287(0.216,0.357)$

$0.137(0.043,0.232)$

Fig. 2 Frequency of PE in patients with COVID-19 who presented at the ED

and PE [32, 40, 44, 45, 71, 74]. However, such an association was not demonstrated in 13 other studies [24, 30, 31, 37, 42, $43,49,50,52,60,62,78]$. Therefore, there are probably other
COVID-19- and host-related factors that are associated with the occurrence of PE. Further studies are required to improve our understanding of the pathophysiology of PE in COVID-

\begin{tabular}{lccc} 
Studies & \multicolumn{2}{c}{ Estimate $(95 \%$ C.I.) } & CovID-19 patients with PE/total \\
& & & \\
Artifoni et al. [25] & 0.206 & $(0.070,0.342)$ & $7 / 34$ \\
Benito et al. [28] & 0.434 & $(0.301,0.567)$ & $23 / 53$ \\
Bompard et al. [30] & 0.180 & $(0.109,0.252)$ & $20 / 111$ \\
Fang et al. [39] & 0.327 & $(0.195,0.458)$ & $16 / 49$ \\
Fauvel et al. [40] & $0.083(0.068,0.098)$ & $103 / 1240$ \\
Grillet et al. [45] & $0.255(0.131,0.380)$ & $12 / 47$ \\
Hamadé et al. [46] & $0.250(0.005,0.495)$ & $3 / 12$ \\
Mouhat et al. [71] & 0.160 & $(0.086,0.234)$ & $15 / 94$ \\
Whyte et al. [11] & 0.324 & $(0.245,0.402)$ & $44 / 136$
\end{tabular}

Overall $\left(I^{\wedge} 2=91 \%, P<0.001\right) \quad 0.239(0.152,0.327)$

$243 / 1776$

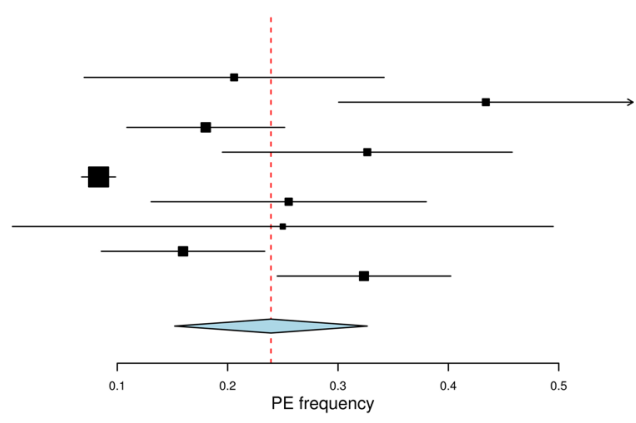

Fig. 3 Frequency of PE in patients with COVID-19 who had been admitted to general wards 
Studies

Alharthy et al. [23] Bellmunt-Montoya et al. [27]

Benito et al. [28]

Bompard et al. [30]

Brüggemann et al. [31]

Contou et al. [35]

Fang et al. [39]

Grillet et al. [45]

Helms et al. [48]

Mak et al. [61]

Mirsadraee et al. [68]

Mouhat et al. [71]

Mueller-Peltzer et al. [72]

Parzy et al. [75]

Patel et al. [76]

Poissy et al. [79]

Schiaffino et al. [83]

Taccone et al. [86]

Thomas et al. [87]

Whyte et al. [11]

Zhang et al. [91]

Zotzmann et al. [92]

Overall $(\mid \wedge 2=80 \%, P<0.001) \quad 0.486(0.410,0.561)$

$0.880(0.753,1.000)$

$0.421(0.264,0.578)$

$0.385(0.120,0.649)$

$0.500(0.300,0.700)$

$0.769(0.540,0.998)$

$0.615(0.428,0.802)$

$0.650(0.441,0.859)$

$0.500(0.321,0.679)$

$0.253(0.167,0.338)$

$0.353(0.222,0.484)$

$0.472(0.357,0.588)$

$0.426(0.309,0.544)$

$0.562(0.319,0.806)$

$0.231(0.002,0.460)$

$0.385(0.232,0.537)$

$0.647(0.486,0.808)$

$0.600(0.457,0.743)$

$0.325(0.180,0.470$

$0.455(0.160,0.749)$

$0.462(0.351,0.572)$

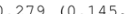

$0.279(0.145,0.413)$
Estimate (95\% C.I.) COVID-19 patients with PE/total number of COVID-19 patients

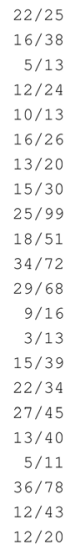

$369 / 818$

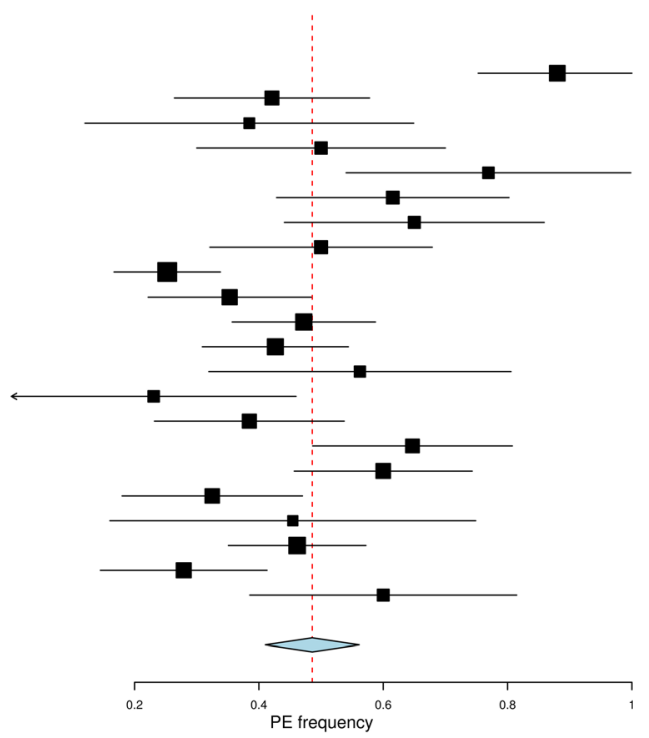

Fig. 4 Frequency of PE in patients with COVID-19 who had been admitted to the ICU

19. Furthermore, the observed frequency of PE depends on the selection criteria for CTPA. In the far majority of included studies, it was reported that CTPA was performed because of clinically suspected PE. In only two studies, CTPA was routinely performed at the ED (regardless of clinical signs of possible PE), with relatively low yields of only $2.1 \%$ and $5.7 \%[29,50]$. In two other studies which routinely performed CTPA in COVID-19 patients at the ICU (regardless of clinical signs of possible PE), PE frequencies were high: $47.2 \%$ and $60.0 \%$, respectively $[68,92]$. These findings in unselected samples of patients confirm that frequency of $\mathrm{PE}$ is higher in ICU patients compared to patients who present at the ED.

Our findings contrast those in patients from the general population without COVID-19, where PE has been reported to occur in main pulmonary arteries as frequent as or more frequently than in peripheral arteries [94-96]. Therefore, the underlying pathomechanisms may be different. The relatively high frequency of peripheral PE suggest that local thrombosis may play a more important role in the development of PE (or pulmonary artery thrombosis) in COVID-19 [37, 55, 97, 98]
Table 3 Sensitivity and specificity values for different $\mathrm{D}$ dimer cutoff levels to diagnose $\mathrm{PE}$

\begin{tabular}{llll}
\hline Study & D-dimer cutoff level & Sensitivity & Specificity \\
\hline Alonso-Fernandez et al [24] & $2500 \mu \mathrm{g} / \mathrm{L}$ & $80 \%$ & $51 \%$ \\
Cerda et al [33] & $2036 \mu \mathrm{g} / \mathrm{L}$ & $75 \%^{\wedge}$ & $69 \%^{\wedge}$ \\
& Age-adjusted cutoff levels & $94 \%^{\wedge}$ & $35 \%^{\wedge}$ \\
Kaminetzky et al [52] & $1394 \mu \mathrm{g} / \mathrm{L}$ & $95 \%$ & $71 \%$ \\
Léonard-Lorant et al [58] & $2660 \mu \mathrm{g} / \mathrm{L}$ & $100 \%$ & $67 \%$ \\
Loffi et al [60] & $2370 \mu \mathrm{g} / \mathrm{L}$ & $70 \%$ & $62 \%$ \\
Mouhat et al [71] & $2590 \mu \mathrm{g} / \mathrm{L}$ & $83 \%$ & $84 \%$ \\
Ooi et al [74] & $2247 \mu \mathrm{g} / \mathrm{L}$ & $72 \%$ & $74 \%$ \\
Planquette et al [78] & $1500 \mu \mathrm{g} / \mathrm{L}$ & $76 \%$ & $65 \%$ \\
Ramadan et al [82] & $2000 \mu \mathrm{g} / \mathrm{L}$ & $78 \% *$ & $67 \% *$ \\
& $1000 \mu \mathrm{g} / \mathrm{L}$ & $63 \% \%^{*}$ & $66 \%^{\#}$ \\
& & $94 \%^{*}$ & $30 \%^{*}$ \\
Taccone et al [86] & & $89 \%^{\#}$ & $23 \%^{\#}$ \\
Ventura-Diaz et al [89] & $3647 \mu \mathrm{g} / \mathrm{L}$ & $75 \%$ & $92 \%$ \\
Whyte et al [11] & $2903 \mu \mathrm{g} / \mathrm{L}$ & $81 \%$ & $59 \%$ \\
\hline
\end{tabular}

*ED patients

\# Inpatients

^3 weeks after COVID-19 symptom onset 


\begin{tabular}{lrrr} 
Studies & \multicolumn{3}{c}{ Est imate (95\% C.I. $)$} \\
Alonso-Fernández et al. [24] & 0.392 & $(-0.331,1.114)$ \\
Brüggemann et al. [31] & 0.631 & $(-0.035,1.297)$ \\
Cavagna et al. [32] & 5.195 & $(4.376,6.014)$ \\
Cerda et al. [33] & 0.713 & $(0.262,1.165)$ \\
Chen et al. [34] & 0.764 & $(-0.064,1.592)$ \\
Contou et al. [35] & 0.080 & $(-0.710$, & $0.871)$ \\
De Cobelli et al. [37] & 0.682 & $(0.138,1.226)$ \\
Espallargas et al. [38] & 0.205 & $(-0.400,0.809)$ \\
Fauvel et al. [40] & 0.518 & $(0.316,0.721)$ \\
García-Ortega et al. [42] & 0.402 & $(-0.082,0.885)$ \\
Gervaise et al. [43] & 0.798 & $(0.184,1.413)$ \\
Hammer et al. [47] & 1.738 & $(1.224,2.252)$ \\
Ippolito et al. [49] & 1.657 & $(1.307,2.006)$ \\
Jalaber et al. [50] & 5.235 & $(3.905,6.566)$ \\
Jevnikar et al. [51] & 1.443 & $(0.825,2.061)$ \\
Kaminetzky et al. [52] & 1.408 & $(0.836,1.980)$ \\
Lang et al. [55] & 1.247 & $(0.407$, & $2.086)$ \\
Loffi et al. [60] & 0.402 & $(0.171$, & $0.633)$ \\
Léonard-Lorant et al. [58] & 1.587 & $(1.120,2.053)$ \\
Meiler et al. [64] & 0.711 & $(0.078,1.344)$ \\
Mouhat et al. [71] & 1.690 & $(1.298,2.083)$ \\
Mueller-Peltzer et al. [72] & 0.850 & $(-0.181,1.881)$ \\
Ooi et al. [74] & 0.747 & $(0.292,1.201)$ \\
Poyiadji et al. [80] & 1.471 & $(1.186,1.756)$ \\
Ramadan et al. [82] (ED patients) & 0.797 & $(0.369,1.225)$ \\
Ramadan et al. [82] (inpatients) & 0.868 & $(0.462,1.274)$ \\
Schiaffino et al. [83] & 0.669 & $(0.057,1.281)$ \\
Taccone et al. [86] & 0.912 & $(0.221,1.603)$ \\
Ventura-Díaz et al. [89] & 0.780 & $(0.497,1.063)$ \\
Whyte et al. [11] & 1.171 & $(0.872,1.469)$ \\
Zotzmann et al. [92] & 0.206 & $(-0.691,1.103)$ \\
Overall (|^2=89\%, P< 0.001) & $\mathbf{1 . 0 9 6}$ & $(0.844,1.349)$
\end{tabular}

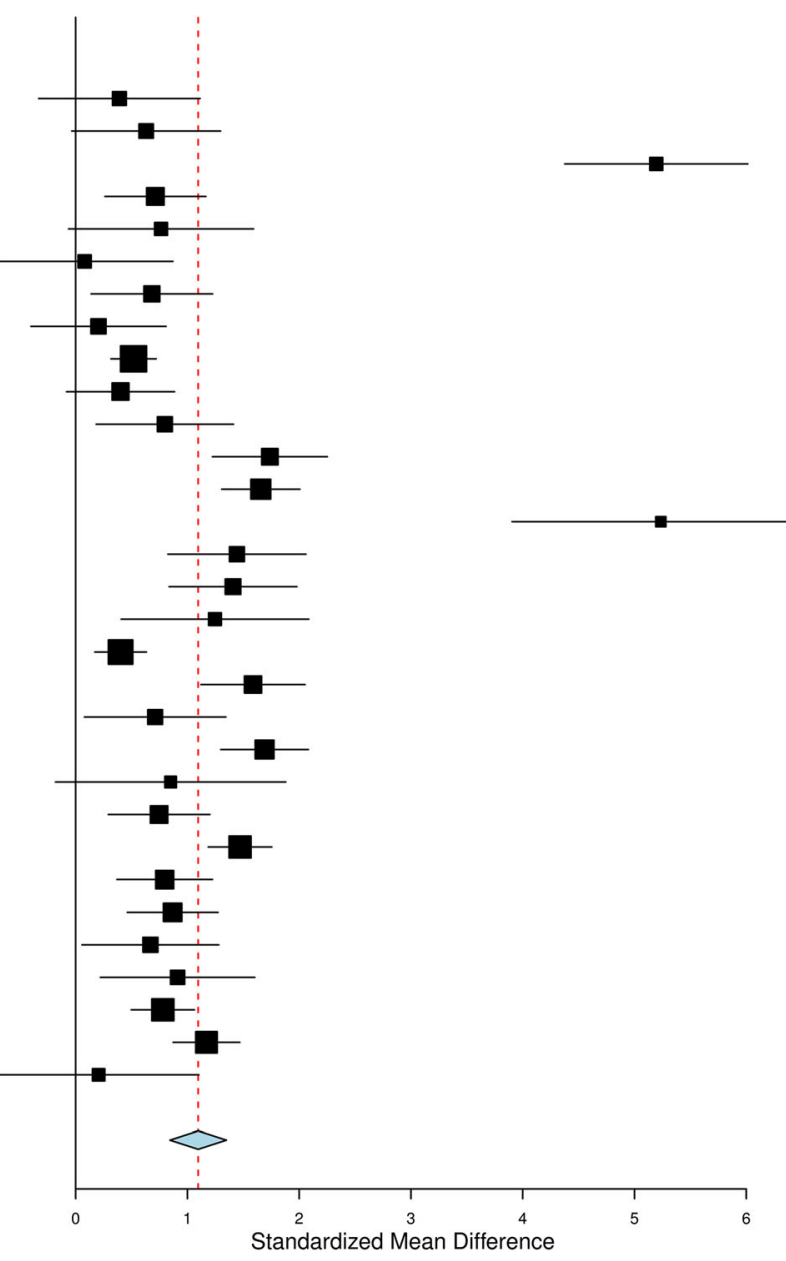

Fig. 5 Association between D-dimer levels and PE in patients with COVID-19

rather than the classic thromboembolism originating from the leg or pelvic veins in patients without COVID-19 [99]. This hypothesis is supported by in vivo chest CT studies, where vascular thickening, a potential sign of vascular inflammation, endothelial damage, and microthrombosis [55], is observed in most symptomatic patients with COVID-19 [100]. Pathological studies in patients with COVID-19 also confirm the local immunothrombosis hypothesis [97, 98]. Accordingly, the term MicroCLOTS (microvascular COVID-19 lung vessels obstructive thromboinflammatory syndrome) has been coined as a new name for severe pulmonary COVID-19, in which alveolar viral damage is followed by an inflammatory reaction and by microthrombosis [97, 101-103]. It may become obsolete to call this pathophysiological disorder PE.

Subgroup analysis did not indicate that the use of antithrombotic prophylaxis was associated with a lower frequency of PE in patients with COVID-19. This implies that physicians should remain alert for the occurrence of PE even in patients who receive antithrombotic prophylaxis. D-dimer levels were found to be significantly higher in patients with PE (pooled
SMD of 1.096), which indicates that a rise in D-dimer levels is not only a marker of pneumonia severity but is also associated with a higher risk of PE. Therefore, D-dimer assessment may help to decide which patients with COVID-19 should undergo CTPA to detect PE. However, there is no uniformly accepted D-dimer threshold to discriminate COVID-19 patients with and without PE. Twelve studies used different D-dimer cutoff levels (varying between 1000 and $4800 \mu \mathrm{g} / \mathrm{L}$ ), yielding sensitivity and specificity values which varied between $63-100 \%$ and $23-84 \%$, respectively $[11,24,33,52,58,60,71,74,78$, $82,86,89]$. These D-dimer cutoff levels were at least twice as high compared to the conventional D-dimer cutoff level of $500 \mu \mathrm{g} / \mathrm{L}$, which is usually employed in the general population as a screening test for venous thromboembolism [104, 105]. In non-COVID-19 patients aged 50 or more, the application of age-adjusted D-dimer cutoffs has shown to increase specificity without modifying sensitivity [106]. Only one of the studies included in our meta-analysis also used ageadjusted D-dimer cutoffs, yielding high sensitivity (94\%) but poor specificity (35\%) [33]. More research is needed to investigate whether the use of age-adjusted D-dimer cutoffs can 
improve the clinical utility of D-dimer testing in patients with COVID-19.

Our study has some limitations. First, in the far majority of included studies, CTPA was only performed in case of clinically suspected PE. Therefore, the true prevalence of PE in patients with COVID-19 remains to be elucidated. Second, due to incomplete and unstandardized reporting, we could not adjust the frequency of PE for well-known risk factors for PE (such as cancer, history of previous venous thromboembolism, duration of hospitalization, obesity, and cardiovascular disease [107]) and type and dosage of antithrombotic prophylaxis. Third, there was a great deal of heterogeneity in the patient population and the indication for CTPA in each included study. Although we attempted to group the studies into ED, general wards, and ICU patients, this delineation may be problematic due to the unpredictable course of COVID-19 and the fact that a patient discharged from the ED could become an ICU ARDS patient within a matter of a week. Furthermore, statistical heterogeneity still remained in each of these groups. Fourth, PE was determined by CTPA, which has a good but not perfect sensitivity in PE detection [9]. Although they may be clinically less relevant [108], smaller subsegmental PEs may have been missed by CTPA. This could have resulted in an underestimation of PE frequency.

In conclusion, the frequency of $\mathrm{PE}$ in patients with COVID-19 is highest in the ICU, followed by general wards and the ED. PE in COVID-19 is more commonly located in peripheral than in central pulmonary arteries, which suggests local thrombosis to play a major role. D-dimer assessment may help to select patients with COVID-19 for CTPA, using D-dimer cutoff levels of at least $1000 \mu \mathrm{g} / \mathrm{L}$.

Supplementary Information The online version contains supplementary material available at https://doi.org/10.1007/s00330-021-08003-8.

Funding The authors state that this work has not received any funding.

\section{Declarations}

Guarantor The scientific guarantor of this publication is Robert Kwee.

Conflict of interest The authors of this manuscript declare no relationships with any companies whose products or services may be related to the subject matter of the article.

Statistics and biometry The authors have significant statistical expertise.

Informed consent Written informed consent was not required for this study because of the meta-analysis.

Ethical approval Institutional Review Board approval was not required because of the meta-analysis.
Methodology

- Multicentre study

\section{References}

1. COVID-19 Dashboard by the Center for Systems Science and Engineering (CSSE) at Johns Hopkins University (JHU). Available via https://coronavirus.jhu.edu/. Accessed 21 Mar 2021

2. World Health Organization Coronavirus disease (COVID-19) Available via https://www.who.int/emergencies/diseases/novelcoronavirus-2019/question-and-answers-hub/q-a-detail/ coronavirus-disease-covid-19. Accessed 21 Mar 2021

3. (2020) COVID-19 and vascular disease. EBioMedicine 58: 102966

4. Wichmann D, Sperhake JP, Lutgehetmann M et al (2020) Autopsy findings and venous thromboembolism in patients with COVID-19: a prospective cohort study. Ann Intern Med 173:268277

5. Oudkerk M, Buller HR, Kuijpers D et al (2020) Diagnosis, prevention, and treatment of thromboembolic complications in COVID-19: report of the National Institute for Public Health of the Netherlands. Radiology 297:E216-E222

6. Lax SF, Skok K, Zechner P et al (2020) Pulmonary arterial thrombosis in COVID-19 with fatal outcome : results from a prospective, single-center, clinicopathologic case series. Ann Intern Med 173:350-361

7. Benzakoun J, Hmeydia G, Delabarde T et al (2020) Excess out-ofhospital deaths during the COVID-19 outbreak: evidence of pulmonary embolism as a main determinant. Eur J Heart Fail 22: 1046-1047

8. NIH COVID-19 Treatment Guidelines. Antithrombotic therapy in patients with COVID-19. Available via https://www. covid19treatmentguidelines.nih.gov/adjunctive-therapy/ antithrombotic-therapy/. Accessed 21 Mar 2021

9. Moore AJE, Wachsmann J, Chamarthy MR, Panjikaran L, Tanabe Y, Rajiah P (2018) Imaging of acute pulmonary embolism: an update. Cardiovasc Diagn Ther 8:225-243

10. Wells PS, Anderson DR, Rodger M et al (2001) Excluding pulmonary embolism at the bedside without diagnostic imaging: management of patients with suspected pulmonary embolism presenting to the emergency department by using a simple clinical model and d-dimer. Ann Intern Med 135:98-107

11. Whyte MB, Kelly PA, Gonzalez E, Arya R, Roberts LN (2020) Pulmonary embolism in hospitalised patients with COVID-19. Thromb Res 195:95-99

12. Lorenzo C, Francesca B, Francesco P, Elena C, Luca S, Paolo S (2020) Acute pulmonary embolism in COVID-19 related hypercoagulability. J Thromb Thrombolysis 50:223-226

13. Jimenez-Guiu X, Huici-Sanchez M, Romera-Villegas A, Izquierdo-Miranda A, Sancho-Cerro A, Vila-Coll R (2020) Deep vein thrombosis in non-critically ill patients with coronavirus disease 2019 pneumonia: deep vein thrombosis in nonintensive care unit patients. J Vasc Surg Venous Lymphat Disord. https://doi.org/10.1016/j.jvsv.2020.08.028

14. Kermani-Alghoraishi M, Ghahramani R (2021) A review of venous thromboembolism phenomena in COVID-19 patients. Curr Probl Cardiol 46:100692

15. Abernethy K, Sivakumar P, Patrick T, Robbie H, Periselneris J (2020) Coexistent COVID-19 pneumonia and pulmonary embolism: challenges in identifying dual pathology. Thorax 75:812814

16. PRISMA Transparent reporting of systematic reviews and metaanalyses. Available via http://www.prisma-statement.org/. Accessed 21 Mar 2021 
17. Wells G, Shea B, O'Connell D et al The Newcastle-Ottawa Scale (NOS) for assessing the quality of nonrandomised studies in metaanalyses. Available via http://www.ohri.ca/programs/clinical_ epidemiology/oxford.asp. Accessed 21 Mar 2021

18. Campbell I (2007) Chi-squared and Fisher-Irwin tests of two-bytwo tables with small sample recommendations. Stat Med 26: 3661-3675

19. Higgins JP, Thompson SG, Deeks JJ, Altman DG (2003) Measuring inconsistency in meta-analyses. BMJ 327:557-560

20. Cochrane Handbook for Systematic Reviews of Interventions

21. OpenMeta[Analyst]. Available via http://www.cebm.brown.edu/ openmeta/. Accessed 21 Mar 2021

22. MedCalc. Available via https://www.medcalc.org/. Accessed 21 Mar 2021

23. Alharthy A, Faqihi F, Abuhamdah M et al (2021) Prospective longitudinal evaluation of point-of-care lung ultrasound in critically ill patients with Severe COVID-19 pneumonia. J Ultrasound Med 40:443-456

24. Alonso-Fernandez A, Toledo-Pons N, Cosio BG et al (2020) Prevalence of pulmonary embolism in patients with COVID-19 pneumonia and high D-dimer values: a prospective study. PLoS One 15:e238216

25. Artifoni M, Danic G, Gautier G et al (2020) Systematic assessment of venous thromboembolism in COVID-19 patients receiving thromboprophylaxis: incidence and role of $\mathrm{D}$-dimer as predictive factors. J Thromb Thrombolysis 50:211-216

26. Baccellieri D, Bertoglio L, Apruzzi L et al (2020) Incidence of deep venous thrombosis in COVID-19 hospitalized patients during the first peak of the Italian outbreak. Phlebology. https://doi. org/10.1177/0268355520975592:268355520975592

27. Bellmunt-Montoya S, Riera C, Gil D et al (2020) COVID-19 infection in critically ill patients carries a high risk of venous thrombo-embolism. Eur J Vasc Endovasc Surg. https://doi.org/ 10.1016/j.ejvs.2020.12.015

28. Benito N, Filella D, Mateo J et al (2020) Pulmonary thrombosis or embolism in a large cohort of hospitalized patients with Covid-19. Front Med (Lausanne) 7:557

29. Birk R, Shaw D, Kennedy C et al (2020) Low detection rate of pulmonary embolism in patients presenting to the emergency department with suspected coronavirus disease 2019 (COVID-19): A Single-Centre UK Study. Curr Probl Diagn Radiol. https://doi. org/10.1067/j.cpradiol.2020.09.014

30. Bompard F, Monnier H, Saab I et al (2020) Pulmonary embolism in patients with COVID-19 pneumonia. Eur Respir J 56

31. Bruggemann RAG, Spaetgens B, Gietema HA et al (2020) The prevalence of pulmonary embolism in patients with COVID-19 and respiratory decline: a three-setting comparison. Thromb Res 196:486-490

32. Cavagna E, Muratore F, Ferrari F (2020) Pulmonary thromboembolism in COVID-19: venous thromboembolism or arterial thrombosis? Radiology: Cardiothoracic Imaging 2:e200277

33. Cerda P, Ribas J, Iriarte A et al (2020) Blood test dynamics in hospitalized COVID-19 patients: potential utility of D-dimer for pulmonary embolism diagnosis. PLoS One 15:e0243533

34. Chen J, Wang X, Zhang S et al (2020) Characteristics of acute pulmonary embolism in patients with COVID-19 associated pneumonia from the city of Wuhan. Clin Appl Thromb Hemost 26: 1076029620936772

35. Contou D, Pajot O, Cally R et al (2020) Pulmonary embolism or thrombosis in ARDS COVID-19 patients: a French monocenter retrospective study. PLoS One 15:e0238413

36. Darwish HS, Habash MY, Habash WY (2021) COVID-19 Viral pneumonia complicated with acute pulmonary embolism: a descriptive study. Radiol Res Pract 2021:6649086
37. De Cobelli F, Palumbo D, Ciceri F et al (2021) Pulmonary vascular thrombosis in COVID-19 pneumonia. J Cardiothorac Vasc Anesth. https://doi.org/10.1053/j.jvca.2021.01.011

38. Espallargas I, Rodriguez Sevilla JJ, Rodriguez Chiaradia DA et al (2020) CT imaging of pulmonary embolism in patients with COVID-19 pneumonia: a retrospective analysis. Eur Radiol. https://doi.org/10.1007/s00330-020-07300-y

39. Fang C, Garzillo G, Batohi B et al (2020) Extent of pulmonary thromboembolic disease in patients with COVID-19 on CT: relationship with pulmonary parenchymal disease. Clin Radiol 75: 780-788

40. Fauvel C, Weizman O, Trimaille A et al (2020) Pulmonary embolism in COVID-19 patients: a French multicentre cohort study. Eur Heart J 41:3058-3068

41. Freund Y, Drogrey M, Miro O et al (2020) association between pulmonary embolism and COVID-19 in emergency department patients undergoing computed tomography pulmonary angiogram: the PEPCOV International Retrospective Study. Acad Emerg Med 27:811-820

42. Garcia-Ortega A, Oscullo G, Calvillo P et al (2021) Incidence, risk factors, and thrombotic load of pulmonary embolism in patients hospitalized for COVID-19 infection. J Infect 82:261-269

43. Gervaise A, Bouzad C, Peroux E, Helissey C (2020) Acute pulmonary embolism in non-hospitalized COVID-19 patients referred to CTPA by emergency department. Eur Radiol 30:61706177

44. Grillet F, Behr J, Calame P, Aubry S, Delabrousse E (2020) Acute pulmonary embolism associated with COVID-19 pneumonia detected with pulmonary CT angiography. Radiology 296:E186E188

45. Grillet F, Busse-Cote A, Calame P, Behr J, Delabrousse E, Aubry S (2020) COVID-19 pneumonia: microvascular disease revealed on pulmonary dual-energy computed tomography angiography. Quant Imaging Med Surg 10:1852-1862

46. Hamade A, Jambert L, Tousch J et al (2020) Systematic duplex ultrasound screening in conventional units for COVID-19 patients with follow-up of 5 days. J Vasc Surg Venous Lymphat Disord. https://doi.org/10.1016/j.jvsv.2020.11.019

47. Hammer MM, Hunsaker AR, Gooptu M, Hatabu H (2020) Frequency of pulmonary embolism in patients with COVID-19. JACC Cardiovasc Imaging 13:2478-2479

48. Helms J, Tacquard C, Severac F et al (2020) High risk of thrombosis in patients with severe SARS-CoV-2 infection: a multicenter prospective cohort study. Intensive Care Med 46:1089-1098

49. Ippolito D, Giandola T, Maino C et al (2021) Acute pulmonary embolism in hospitalized patients with SARS-CoV-2-related pneumonia: multicentric experience from Italian endemic area. Radiol Med. https://doi.org/10.1007/s11547-020-01328-2:1-10

50. Jalaber C, Revel MP, Chassagnon G et al (2020) Role of upfront CT pulmonary angiography at admission in COVID-19 patients. Thromb Res 196:138-140

51. Jevnikar M, Sanchez O, Chocron R et al (2021) Prevalence of pulmonary embolism in patients with COVID 19 at the time of hospital admission. Eur Respir J. https://doi.org/10.1183/ 13993003.00116-2021

52. Kaminetzky M, Moore W, Fansiwala K et al (2020) Pulmonary embolism at CT pulmonary angiography in patients with COVID19. Radiology: Cardiothoracic Imaging 2:e200277

53. Khan MZ, Jamal Y, Sutton B, Rauf F (2020) Venous thromboembolism in patients with COVID-19 and correlation with D-dimers: a single-centre experience. BMJ Open Respir Res 7

54. Kirsch B, Aziz M, Kumar S et al (2020) Wells score to predict pulmonary embolism in patients with coronavirus disease 2019. Am J Med. https://doi.org/10.1016/j.amjmed.2020.10.044 
55. Lang M, Som A, Carey D et al (2020) Pulmonary vascular manifestations of COVID-19 pneumonia. Radiology Cardiothoracic Imaging 2:200277

56. Larsen K, Coolen-Allou N, Masse L et al (2020) Detection of pulmonary embolism in returning travelers with hypoxemic pneumonia due to COVID-19 in Reunion Island. Am J Trop Med Hyg 103:844-846

57. Lee E, Krajewski A, Clarke C, O'Sullivan D, Herbst T, Lee S (2021) Arterial and venous thromboembolic complications of COVID-19 detected by CT angiogram and venous duplex ultrasound. Emerg Radiol. https://doi.org/10.1007/s10140-020-01884-0

58. Leonard-Lorant I, Delabranche X, Severac F et al (2020) acute pulmonary embolism in patients with COVID-19 at CT angiography and relationship to d-dimer levels. Radiology 296:E189E191

59. Lodigiani C, Iapichino G, Carenzo L et al (2020) Venous and arterial thromboembolic complications in COVID-19 patients admitted to an academic hospital in Milan, Italy. Thromb Res 191:914

60. Loffi M, Regazzoni V, Toselli M et al (2021) Incidence and characterization of acute pulmonary embolism in patients with SARSCoV-2 pneumonia: a multicenter Italian experience. PLoS One 16:e 0245565

61. Mak SM, Mak D, Hodson D et al (2020) Pulmonary ischaemia without pulmonary arterial thrombus in COVID-19 patients receiving extracorporeal membrane oxygenation: a cohort study. Clin Radiol 75:795.e791-795.e795

62. Martinez Chamorro E, Revilla Ostolaza TY, Perez Nunez M, Borruel Nacenta S, Cruz-Conde Rodriguez-Guerra C, Ibanez Sanz L (2021) Pulmonary embolisms in patients with COVID19: a prevalence study in a tertiary hospital. Radiologia 63:13-21

63. Martini K, Bluthgen C, Walter JE, Nguyen-Kim TDL, Thienemann F, Frauenfelder T (2020) Patterns of organizing pneumonia and microinfarcts as surrogate for endothelial disruption and microangiopathic thromboembolic events in patients with coronavirus disease 2019. PLoS One 15:e0240078

64. Meiler S, Hamer OW, Schaible J et al (2020) Computed tomography characterization and outcome evaluation of COVID-19 pneumonia complicated by venous thromboembolism. PLoS One 15:e242475

65. Mestre-Gomez B, Lorente-Ramos RM, Rogado J et al (2021) Incidence of pulmonary embolism in non-critically ill COVID19 patients. Predicting factors for a challenging diagnosis. J Thromb Thrombolysis 51:40-46

66. Minuz P, Mansueto G, Mazzaferri F et al (2020) High rate of pulmonary thromboembolism in patients with SARS-CoV-2 pneumonia. Clin Microbiol Infect 26:1572-1573

67. Miro O, Llorens P, Aguirre A et al (2020) Association between Covid-19 and Pulmonary Embolism (AC-19-PE study). Thromb Res 196:322-324

68. Mirsadraee S, Gorog DA, Mahon CF et al (2021) Prevalence of thrombotic complications in ICU-treated patients with coronavirus disease 2019 detected with systematic CT scanning. Crit Care Med. https://doi.org/10.1097/CCM.0000000000004890

69. Moll M, Zon RL, Sylvester KW et al (2020) VTE in ICU Patients With COVID-19. Chest 158:2130-2135

70. Monfardini L, Morassi M, Botti P et al (2020) Pulmonary thromboembolism in hospitalised COVID-19 patients at moderate to high risk by Wells score: a report from Lombardy, Italy. Br J Radiol 93:20200407

71. Mouhat B, Besutti M, Bouiller K et al (2020) Elevated D-dimers and lack of anticoagulation predict PE in severe COVID-19 patients. Eur Respir J 56

72. Mueller-Peltzer K, Krauss T, Benndorf M et al (2020) Pulmonary artery thrombi are co-located with opacifications in SARS-CoV2 induced ARDS. Respir Med 172:106135
73. O'Shea A, Parakh A, Hedgire S, Lee SI (2021) Multisystem assessment of the imaging manifestations of coagulopathy in hospitalized patients with coronavirus disease (COVID-19). AJR Am J Roentgenol. https://doi.org/10.2214/AJR.20.24132:1-9

74. Ooi MWX, Rajai A, Patel R, Gerova N, Godhamgaonkar V, Liong SY (2020) Pulmonary thromboembolic disease in COVID-19 patients on CT pulmonary angiography - prevalence, pattern of disease and relationship to D-dimer. Eur J Radiol 132: 109336

75. Parzy G, Daviet F, Puech B et al (2020) Venous thromboembolism events following venovenous extracorporeal membrane oxygenation for severe acute respiratory syndrome coronavirus 2 based on CT scans. Crit Care Med 48:e971-e975

76. Patel BV, Arachchillage DJ, Ridge CA et al (2020) Pulmonary angiopathy in severe COVID-19: physiologic, imaging, and hematologic observations. Am J Respir Crit Care Med 202:690-699

77. Perez Duenas V, Allona Krauel M, Agrela Rojas E et al (2021) Blue lungs in Covid-19 patients: a step beyond the diagnosis of pulmonary thromboembolism using MDCT with iodine mapping. Arch Bronconeumol 57(Suppl 1):35-46

78. Planquette B, Le Berre A, Khider L et al (2021) Prevalence and characteristics of pulmonary embolism in 1042 COVID-19 patients with respiratory symptoms: a nested case-control study. Thromb Res 197:94-99

79. Poissy J, Goutay J, Caplan M et al (2020) pulmonary embolism in patients with COVID-19: awareness of an increased prevalence. Circulation 142:184-186

80. Poyiadji N, Cormier P, Patel PY et al (2020) Acute pulmonary embolism and COVID-19. Radiology 297:E335-E338

81. Rali P, O'Corragain O, Oresanya L et al (2020) Incidence of venous thromboembolism in coronavirus disease 2019: an experience from a single large academic center. J Vasc Surg Venous Lymphat Disord. https://doi.org/10.1016/j.jvsv.2020.09.006

82. Ramadan L, Koziatek CA, Caldwell JR et al (2020) Pulmonary thromboembolism in COVID-19: evaluating the role of D-dimer and computed tomography pulmonary angiography results. Am J Emerg Med. https://doi.org/10.1016/j.ajem.2020.08.096

83. Schiaffino S, Giacomazzi F, Esseridou A et al (2021) Pulmonary thromboembolism in coronavirus disease 2019 patients undergoing thromboprophylaxis. Medicine (Baltimore) 100:e24002

84. Scialpi M, Sielaszuk EB, Vitale ME, Scalera GB, Nicola R, Mancioli FA (2021) Pulmonary embolism in COVID-19: ancillary findings on chest CT angiography. Lung India 38:S123-S125

85. Shahin Y, Rajaram S, Parkash V, Wild JM, Kiely DG, Swift AJ (2021) Patterns of thromboembolic pulmonary vascular disease in COVID-19. Pulm Circ 11:2045894020979198

86. Taccone FS, Gevenois PA, Peluso L et al (2020) Higher intensity thromboprophylaxis regimens and pulmonary embolism in critically ill coronavirus disease 2019 patients. Crit Care Med 48: e1087-e1090

87. Thomas W, Varley J, Johnston A et al (2020) Thrombotic complications of patients admitted to intensive care with COVID-19 at a teaching hospital in the United Kingdom. Thromb Res 191:7677

88. Tung-Chen Y, Martí de Gracia M, Díez-Tascón A et al (2020) Correlation between chest computed tomography and lung ultrasonography in patients with coronavirus disease 2019 (COVID19). Ultrasound Med Biol 46:2918-2926

89. Ventura-Diaz S, Quintana-Perez JV, Gil-Boronat A et al (2020) A higher D-dimer threshold for predicting pulmonary embolism in patients with COVID-19: a retrospective study. Emerg Radiol 27: 679-689

90. Vlachou M, Drebes A, Candilio L et al (2021) Pulmonary thrombosis in Covid-19: before, during and after hospital admission. J Thromb Thrombolysis. https://doi.org/10.1007/s11239-02002370-7 
91. Zhang J, Merrick B, Correa GL et al (2020) Veno-venous extracorporeal membrane oxygenation in coronavirus disease 2019: a case series. ERJ Open Res 6

92. Zotzmann V, Lang CN, Wengenmayer T et al (2020) Combining lung ultrasound and Wells score for diagnosing pulmonary embolism in critically ill COVID-19 patients. J Thromb Thrombolysis. https://doi.org/10.1007/s11239-020-02323-0

93. Konstantinides SV, Meyer G, Becattini C et al (2020) 2019 ESC Guidelines for the diagnosis and management of acute pulmonary embolism developed in collaboration with the European Respiratory Society (ERS). Eur Heart J 41:543-603

94. Alonso Martinez JL, Anniccherico Sanchez FJ, Urbieta Echezarreta MA, Garcia IV, Alvaro JR (2016) Central versus peripheral pulmonary embolism: analysis of the impact on the physiological parameters and long-term survival. N Am J Med Sci 8:134-142

95. Cha SI, Shin KM, Lee JW et al (2010) Clinical characteristics of patients with peripheral pulmonary embolism. Respiration 80: 500-508

96. Jain CC, Chang Y, Kabrhel C et al (2017) Impact of pulmonary arterial clot location on pulmonary embolism treatment and outcomes (90 days). Am J Cardiol 119:802-807

97. Ciceri F, Beretta L, Scandroglio AM et al (2020) Microvascular COVID-19 lung vessels obstructive thromboinflammatory syndrome (MicroCLOTS): an atypical acute respiratory distress syndrome working hypothesis. Crit Care Resusc 22:95-97

98. Gasecka A, Borovac JA, Guerreiro RA et al (2020) Thrombotic Complications in Patients WITH COVID-19: pathophysiological mechanisms, diagnosis, and treatment. Cardiovasc Drugs Ther. https://doi.org/10.1007/s10557-020-07084-9

99. Turetz M, Sideris AT, Friedman OA, Triphathi N, Horowitz JM (2018) Epidemiology, pathophysiology, and natural history of pulmonary embolism. Semin Intervent Radiol 35:92-98
100. Adams HJA, Kwee TC, Yakar D, Hope MD, Kwee RM (2020) Chest CT imaging signature of coronavirus disease 2019 infection: in pursuit of the scientific evidence. Chest 158:1885-1895

101. Renzi S, Landoni G, Zangrillo A, Ciceri F (2020) MicroCLOTS pathophysiology in COVID 19. Korean J Intern Med. https://doi. org $/ 10.3904 / \mathrm{kjim} .2020 .336$

102. Turi S, Nardelli P, Landoni G (2020) Anticoagulants and immunosuppressants in COVID-19: bullets to Defeat MicroCLOTS. Ann Card Anaesth 23:258-259

103. Piemonti L, Landoni G (2020) COVID-19 and islet transplantation: different twins. Am J Transplant 20:2983-2988

104. Pulivarthi S, Gurram MK (2014) Effectiveness of d-dimer as a screening test for venous thromboembolism: an update. $\mathrm{N} \mathrm{Am} \mathrm{J}$ Med Sci 6:491-499

105. Schols AMR, Meijs E, Dinant GJ, Stoffers H, Krekels MME, Cals JWL (2019) General practitioner use of D-dimer in suspected venous thromboembolism: historical cohort study in one geographical region in the Netherlands. BMJ Open 9:e026846

106. Schouten HJ, Geersing GJ, Koek HL et al (2013) Diagnostic accuracy of conventional or age adjusted D-dimer cut-off values in older patients with suspected venous thromboembolism: systematic review and meta-analysis. BMJ 346:f2492

107. Belohlavek J, Dytrych V, Linhart A (2013) Pulmonary embolism, part I: Epidemiology, risk factors and risk stratification, pathophysiology, clinical presentation, diagnosis and nonthrombotic pulmonary embolism. Exp Clin Cardiol 18:129-138

108. Carrier M, Righini M, Wells PS et al (2010) Subsegmental pulmonary embolism diagnosed by computed tomography: incidence and clinical implications. A systematic review and meta-analysis of the management outcome studies. J Thromb Haemost 8:1716-1722

Publisher's note Springer Nature remains neutral with regard to jurisdictional claims in published maps and institutional affiliations. 